\title{
WestVirginiaUniversity
}

THE RESEARCH REPOSITORY @ WVU

Graduate Theses, Dissertations, and Problem Reports

2010

\section{Prediction for Resolution Time of Software Defect}

Da Wang

West Virginia University

Follow this and additional works at: https://researchrepository.wvu.edu/etd

\section{Recommended Citation}

Wang, Da, "Prediction for Resolution Time of Software Defect" (2010). Graduate Theses, Dissertations, and Problem Reports. 3072.

https://researchrepository.wvu.edu/etd/3072

This Thesis is protected by copyright and/or related rights. It has been brought to you by the The Research Repository @ WVU with permission from the rights-holder(s). You are free to use this Thesis in any way that is permitted by the copyright and related rights legislation that applies to your use. For other uses you must obtain permission from the rights-holder(s) directly, unless additional rights are indicated by a Creative Commons license in the record and/ or on the work itself. This Thesis has been accepted for inclusion in WVU Graduate Theses, Dissertations, and Problem Reports collection by an authorized administrator of The Research Repository @ WVU. For more information, please contact researchrepository@mail.wvu.edu. 


\title{
Prediction for Resolution Time of Software Defect
}

\author{
Da Wang
}

\author{
Problem Report submitted to the \\ College of Engineering and Mineral Resources \\ at West Virginia University \\ in partial fulfillment of the requirements \\ for the degree of \\ Master of Science \\ in \\ Electrical Engineering
}

Bojan Cukic, Ph.D., Chair

Tim Menzies, Ph.D.

James Harner, Ph.D.

Lane Department of Computer Science and Electrical Engineering Morgantown, West Virginia 2010

Keyword: Software Engineering, Data Mining, Random Forest, Prediction

Copyright 2010 Da Wang 


\title{
ABSTRACT \\ Prediction for Resolution Time of Software Defect
}

\author{
Da Wang
}

In practical software development projects, solving test issues efficiently during Software Development Life Cycle is critical to release software products on time. Different test environments, test resources and test requirements could result in different outcomes. Therefore, getting accurate prediction of the software defects' resolution time could be beneficial to the practical projects. .

In our study, data mining techniques offer great promise in prediction of software defects' resolution time. Our research is conducted based on the NASA Metrics Data Program (MDP). We first calculate the resolution time for available projects. Using unsupervised discretization methods, we split resolution time into certain interval as response variable. Then, investigating the relationship between metric properties and time intervals, we fit a model that attempts to produce prediction on resolution time. Experiments and analysis successfully demonstrate the feasibility of our approach. 


\section{ACKNOWLEDGMENTS}

I would like to acknowledge my family for their support during this time. In addition, I would like to thank my advisor Dr. Bojan Cukic and my advisory committee for their continual advice and encouragement. 


\section{Contents}

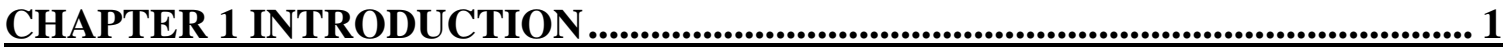

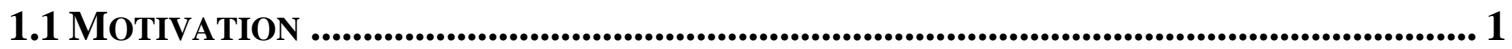

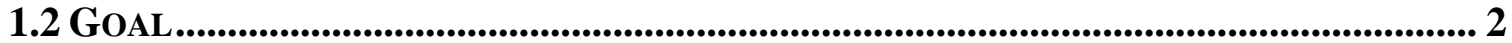

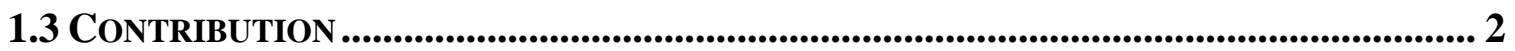

1.4 ORGANIZATION..................................................................................................... 2

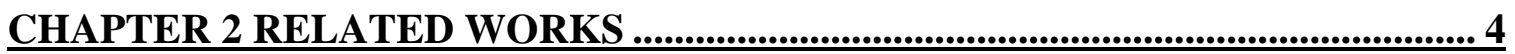

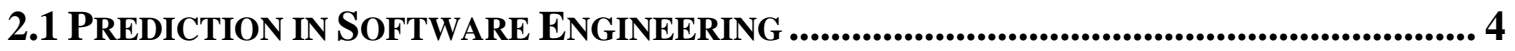

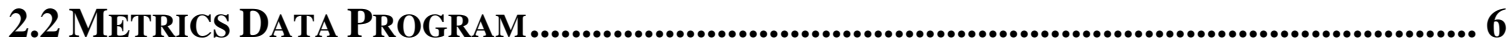

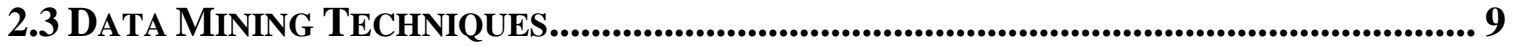

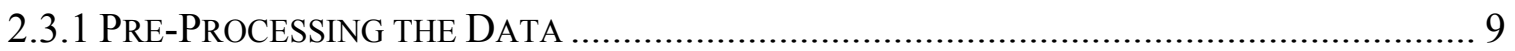

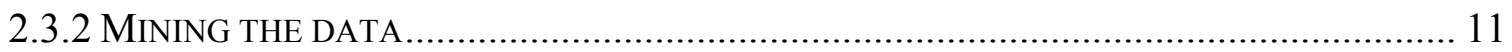

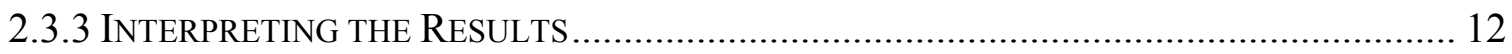

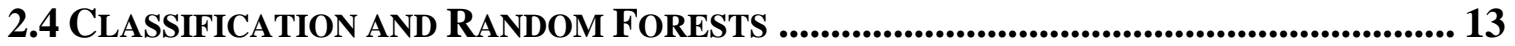

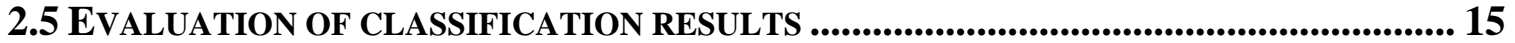

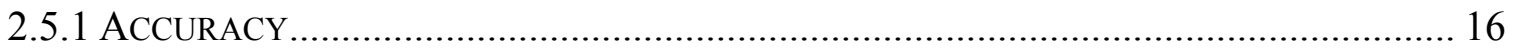

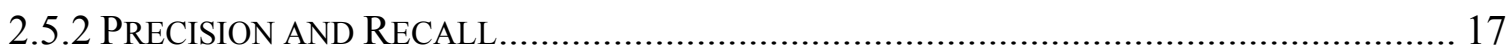

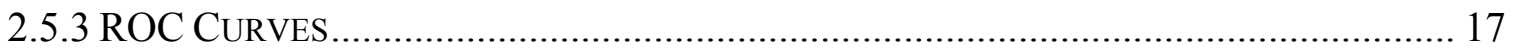

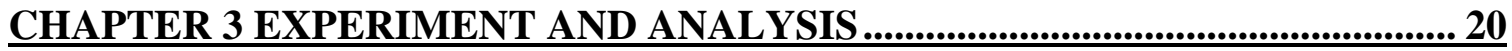

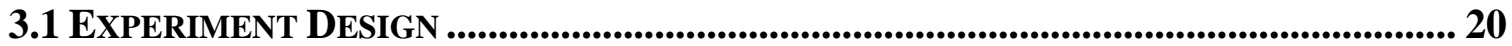

3.2 DISTRIBUTION OF RESPONSE VARIABLE (RESOLUTION TIME) ............................. 21

3.3 EQUAL FREQUNCY VS EQUAL WIDTH .............................................................. 23

3.4 3 BIN EQUAL FREQUENCY FOR ALL DATASETS.......................................................... 26

3.5 5BIN EQUAL FREQUENCY VS 3BIN VS 2BIN ............................................................. 30

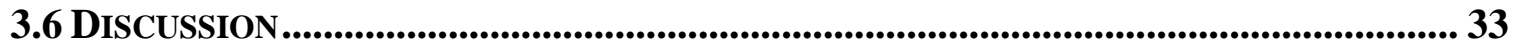

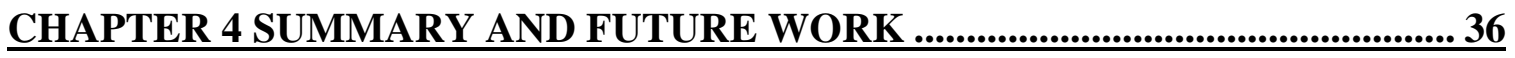

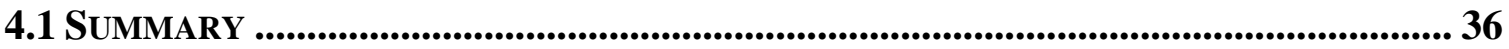

4.2 FUTURE WORK ................................................................................................................................. 37

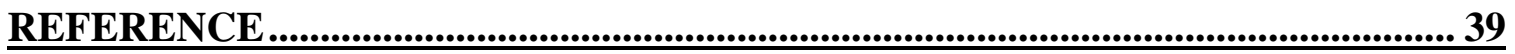




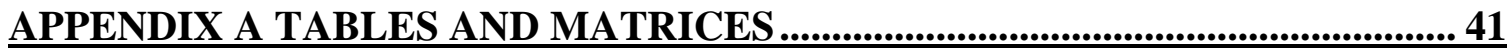




\section{List of Figures}

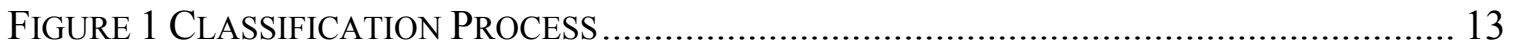

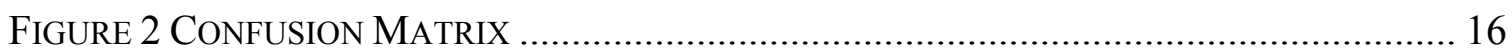

FigURE 3 BOXPLOTS OF RESOLUTION TIME ................................................................. 23

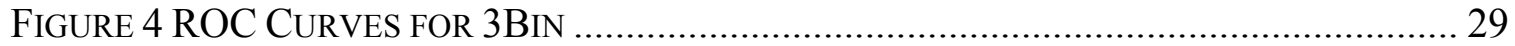

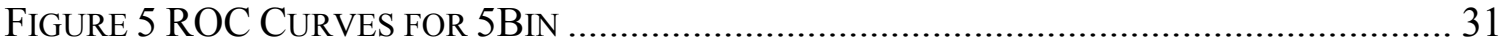

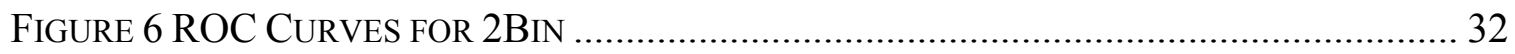

FIGURE 7 PERFORMANCE COMPARISON BOXPLOT ......................................................... 35 


\section{List of Tables}

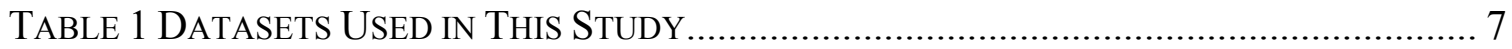

TABLE 2 METRICS USED IN THIS STUDY [1] .......................................................... 9

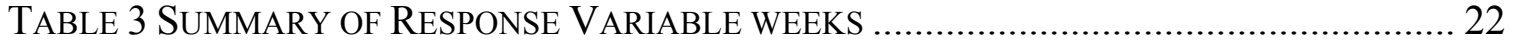

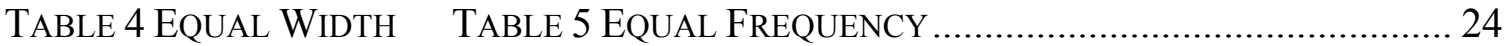

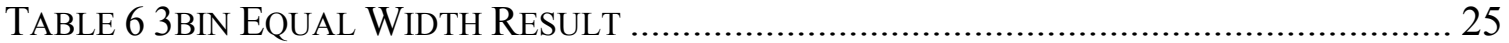

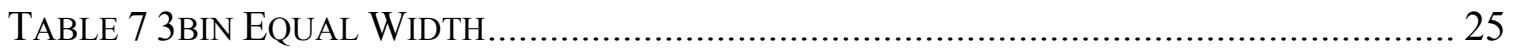

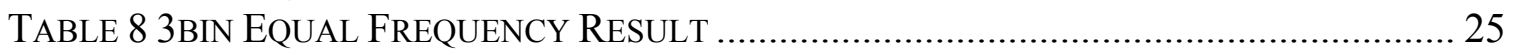

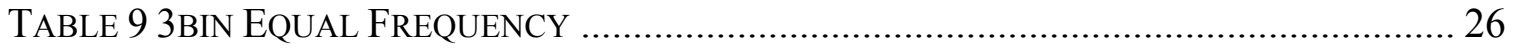

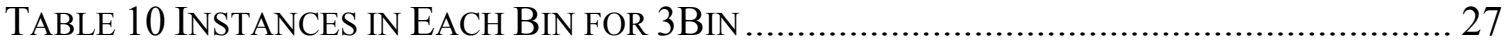

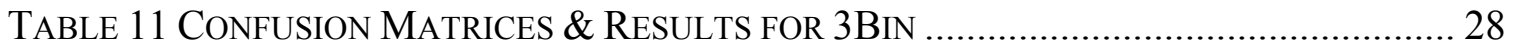

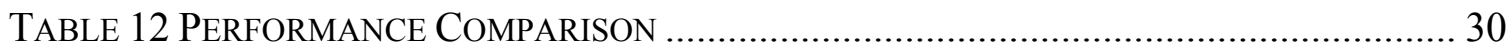

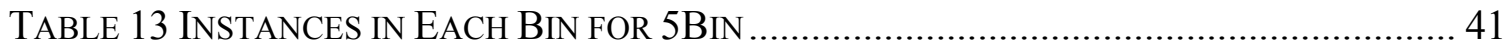

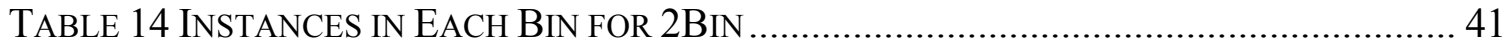

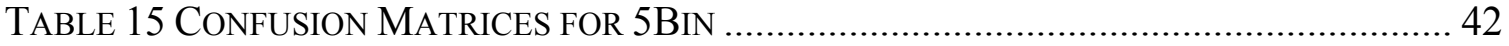

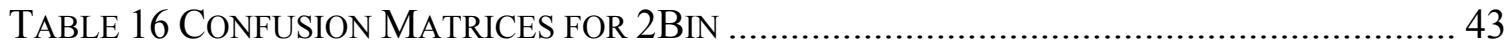




\section{Chapter 1 Introduction}

\subsection{Motivation}

In practical software development projects, controlling the Software Development Life Cycle (SDLC), especially the software test period, and then release the software on time would be a difficult challenge for project managers. Different test environments, test resources and test requirements could result in different outcomes for software test period, thereby the whole SDLC. Therefore, getting accurate prediction of the software defects' resolution time could be beneficial to the practical projects..

In this study, we want to investigate proper methodology to generate accurate prediction of resolution time based on metrics properties, such as the number of operators in a modul, the number of decision points, design density, design complexity, and other attributes, in our datasets.

Data mining techniques have been used in software engineering area for many years. In software quality assurance area, the fault-prone module prediction is one of the topics that many researchers are interested in [1]. Module metrics have been successfully used for predicting fault-prone modules. A study of data mining in module metrics, which is the topic of our research, will be effective for predicting resolution time of software defects accurately. 


\subsection{Goal}

Based on previous motivation, the goal of this study is to provide evidence that we could get an accurate prediction for resolution time of software defects after implementing data mining techniques in module metric datasets. We do not have related literature that can be used as reference to guide our research. Thus we need to design our own experiments and validate the assumption in our models. After comparing the performance of different models we can confirm an optimal solution to predict resolution time of software defects accurately.

\subsection{Contribution}

To build prediction model about software defects' resolution time, a series

of experiments studying on NASA Metrics Data Program (MDP) are conducted in this thesis to find the potential relationship between software metrics and defect resolution time. The result shows that with appropriate algorithm and methodology we may achieve a good model to predict the resolution time on the basis of metrics data.

\subsection{Organization}

The rest of the thesis is organized as follows. Chapter 2 presents a literature review, which covers the usage of prediction in software engineering area as well as the general information about the data sets in MDP depository and general idea of data mining techniques. It also mentions the classification method, Random Forest algorithm and the evaluation of classification results, 
which are utilized in this study. Chapter 3 illustrates the experiment result and conducts the evaluation and discussion on the result. Finally, Chapter 4 provides the conclusion and discusses the methods that can be implemented to further optimize the analysis. 


\section{Chapter 2 Related Works}

\subsection{Prediction in Software Engineering}

As more data are gathered, with the amount of data doubling every three years, data mining is becoming a significant important tool to transform data into information. Although M. Mendonca and N. L. Sunderhaft have applied data mining techniques on software engineering data during 1990s [2], the idea of using data mining skills has attracted a great deal of interest recently within software engineering. We could dig into software engineering data (such as code bases, execution traces, historical code changes, and bug databases) to find out a large amount of information about a software project's status, progress, and evolution. Using this wealth of information could help us on programming, static defect detection, testing, debugging, and maintenance tasks in software engineering.

In software engineering field, many different data mining techniques (such as association rules, classification, and clustering) have been utilized to analyze the data [3].

Studying association rules that identify library components that are often used by application components could be helpful in discovering library reuse patterns in user-selected applications [4]. In 1999, Amir Michail proposed to explore data mining techniques which are designed to find patterns in vast collections of data. The association rules can help a developer discover patterns for reusing library components. Moreover, these rules can be used 
to warn developers automatically when their application reuses library components in a different way from others'.

Classifying data could help do prediction in software engineering field. Amir Michail and Tao Xie used a tool-based approach to help users avoid bugs in GUI applications [5]. In this approach, it incorporates Distance Weighted Nearest Neighbor Learner in the tool to generate bug prediction (bug or not bug) automated. This idea makes sure the user could use the application normally and report defect that they encounter to prevent anyone from encountering those defects again.

Software failure prediction could also be executed by cluster analysis of execution profiles [6]. Andy Podgurski, et al, [7, 8], suggested that using cluster filtering together with stratified random sampling could estimate software reliability efficiently. William Dickinson, et al, [6], evaluated the effectiveness of this method for finding failures. The results show that cluster filtering is a more effective approach for identifying failures in populations of operational executions than simple random sampling.

Besides association rules, classification, and clustering, other methods are also widely used in software engineering area, such as texting mining used for static code analysis [9], and texting mining used for bug report analysis $[10]$. 


\subsection{Metrics Data Program}

The data sets used in this study come from the NASA Metrics Data Program (MDP) data repository [22]. Thirteen projects shown in Table 1 are used in this study. Same data sets are available through the PROMISE [25] repository too.

These data sets provide module metrics that describe 13 different NASA projects. In this study, since we need to predict the defect resolution time period for each project, the projects without resolution time would be removed. Projects MC1, MC2 and PC5, which contain no date data, are not used. Moreover, the number of faulty modules in projects KC3, MW1 and PC2 are 25, 27 and 22 instances respectively, too small sample to predict result correctly. We ignore these three projects too.

The remaining seven data sets contain defect_id, entry_type and entry_date attributes. We calculate the resolution time for each defect and divide the values by seven to generate a new attribute weeks as predicted variable. We confirm that only the longest resolution time exists for each module, and then remove module_id, defect_id, entry_type and entry_date metrics prior to modeling. After removing and replacing these attributes, $\mathrm{KC} 1$ has 22 attributes that can be used as predictor variables, JM1 has 25, and the other five data sets have 44 metrics.

Reverse engineering tool calculates metrics from flowcharts [23], dividing the module metrics into three groups: design, code and other metrics (see table 2) [1]. We use all the metrics in our study, regardless of the metric 
groups. In future work, we may study metric groups separately. It could lead to further research on the relationship between metrics properties and our response variable.

\begin{tabular}{|c|c|c|c|c|c|c|}
\hline Data & Modules & $\begin{array}{l}\% \\
\text { Faulty }\end{array}$ & $\begin{array}{l}\text { \# of Faulty } \\
\text { Modules }\end{array}$ & $\begin{array}{l}\# \text { of FM } \\
\text { with } \\
\text { Resolution } \\
\text { Time }\end{array}$ & Project Description & Lang. \\
\hline CM1 & 505 & $16.04 \%$ & 81 & 75 & Spacecraft instrument & $\mathrm{C}$ \\
\hline $\mathrm{KC} 1$ & 2407 & $12.17 \%$ & 293 & 286 & $\begin{array}{l}\text { Storage management for } \\
\text { receiving/processing } \\
\text { ground data }\end{array}$ & $\mathrm{C}++$ \\
\hline KC4 & 125 & $48 \%$ & 60 & 57 & $\begin{array}{l}\text { A ground-based } \\
\text { subscription server }\end{array}$ & Perl \\
\hline $\mathrm{PC} 1$ & 1107 & $6.59 \%$ & 73 & 63 & $\begin{array}{l}\text { Flight software from an } \\
\text { earth orbiting satellite }\end{array}$ & $\mathrm{C}$ \\
\hline PC3 & 1563 & $10.23 \%$ & 160 & 160 & $\begin{array}{l}\text { Flight software for earth } \\
\text { orbiting satellite }\end{array}$ & $\mathrm{C}$ \\
\hline PC4 & 1458 & $12.24 \%$ & 178 & 178 & $\begin{array}{l}\text { Flight software for earth } \\
\text { orbiting satellite }\end{array}$ & $\mathrm{C}$ \\
\hline JM1 & 10878 & $18.34 \%$ & 1995 & 1350 & $\begin{array}{l}\text { A real time predictive } \\
\text { ground system }\end{array}$ & $\mathrm{C}$ \\
\hline $\mathrm{MC} 2$ & 161 & $32.30 \%$ & NA & $\begin{array}{l}\text { No date } \\
\text { data }\end{array}$ & A video guidance system & $\mathrm{C}++$ \\
\hline $\mathrm{MC1}$ & 9466 & $0.64 \%$ & NA & $\begin{array}{l}\text { No closed } \\
\text { date for } \\
\text { faults }\end{array}$ & $\begin{array}{l}\text { A combustion experiment } \\
\text { of a space shuttle }\end{array}$ & $\mathrm{C}(\mathrm{C}++)$ \\
\hline PC5 & 17186 & $3.00 \%$ & NA & $\begin{array}{l}\text { No date } \\
\text { data }\end{array}$ & $\begin{array}{l}\text { A safety enhancement of a } \\
\text { cockpit upgrade system }\end{array}$ & $\mathrm{C}++$ \\
\hline $\mathrm{KC} 3$ & 458 & $6.3 \%$ & 29 & 25 & $\begin{array}{l}\text { Storage management for } \\
\text { ground data }\end{array}$ & Java \\
\hline MW1 & 433 & $6.24 \%$ & 27 & 27 & $\begin{array}{l}\text { A zero gravity experiment } \\
\text { related to combustion }\end{array}$ & $\mathrm{C}$ \\
\hline $\mathrm{PC} 2$ & 5589 & $0.393 \%$ & 22 & 22 & $\begin{array}{l}\text { Dynamic simulator for } \\
\text { attitude control systems }\end{array}$ & $\mathrm{C}$ \\
\hline
\end{tabular}

Table 1 Datasets Used in This Study 


\begin{tabular}{|c|c|c|}
\hline group & metrics & description or formula \\
\hline \multirow{20}{*}{ code } & PARAMETER_COUNT & Number of parameters to a given module \\
\hline & NUM_OPERATORS:N1 & The number of operators contained in a module \\
\hline & NUM_OPERANDS:N2 & The number of operands contained in a module \\
\hline & NUM_UNIQUE_OPERATORS: $\mu 1$ & The number of unique operators contained in a module \\
\hline & NUM_UNIQUE_OPERANDS: $\mu 2$ & The number of unique operands contained in a module \\
\hline & HALSTEAD_CONTENT: $\mu$ & The halstead length content of a module $\mu=\mu 1+\mu 2$ \\
\hline & HALSTEAD_LENGTH:N & The halstead length metric of a module $\mathrm{N}=\mathrm{N} 1+\mathrm{N} 2$ \\
\hline & HALSTEAD_LEVEL:L & The halstead level metric of a module $\mathrm{L}=2 * \mu 2 /(\mu 1 * \mathrm{~N} 2)$ \\
\hline & HALSTEAD_DIFFICULTY:D & The halstead difficulty metric of a module $\mathrm{D}=1 / \mathrm{L}$ \\
\hline & HALSTEAD_VOLUME:V & The halstead volume metric of a module $\mathrm{V}=\mathrm{N} * \log 2(\mu 1+\mu 2)$ \\
\hline & HALSTEAD_EFFORT:E & The halstead effort metric of a module $\mathrm{E}=\mathrm{V} / \mathrm{L}$ \\
\hline & HALSTEAD_PROG_TIME: T & The halstead programming time metric of a module $\mathrm{T}=\mathrm{E} / 18$ \\
\hline & HALSTEAD_ERROR_EST: B & The halstead error estimate metric of a module $\mathrm{B}=\mathrm{E}^{\wedge}(2 / 3) / 1000$ \\
\hline & NUMBER_OF_LINES & Number of lines in a module \\
\hline & LOC_BLANK & The number of blank lines in a module \\
\hline & $\begin{array}{l}\text { LOC_CODE_AND_COMMENT:NCSL } \\
\text { OC }\end{array}$ & $\begin{array}{l}\text { The number of lines which contain both code and comment in a } \\
\text { module }\end{array}$ \\
\hline & LOC_COMMENTS & The number of lines of comments in a module \\
\hline & LOC_EXECUTABLE & $\begin{array}{l}\text { The number of lines of executable code for a module (not blank or } \\
\text { comment) }\end{array}$ \\
\hline & PERCENT_COMMENTS & Percentage of the code that is comments \\
\hline & LOC_TOTAL & The total number of lines for a given module \\
\hline \multirow{16}{*}{ design } & EDGE_COUNT:e & $\begin{array}{l}\text { Number of edges found in a given module control from one module to } \\
\text { another }\end{array}$ \\
\hline & NODE_COUNT:n & Number of nodes found in a given module \\
\hline & BRANCH_COUNT & Branch count metrics \\
\hline & CALL_PAIRS & Number of calls to other functions in a module \\
\hline & CONDITION_COUNT & Number of conditionals in a given module \\
\hline & CYCLOMATIC_COMPLEXITY: v(G) & The cyclomatic complexity of a module $\mathrm{v}(\mathrm{G})=\mathrm{e}-\mathrm{n}+2$ \\
\hline & DECISION_COUNT & Number of decision points in a given module \\
\hline & DECISION_DENSITY & Condition_count/Decision_count \\
\hline & DESIGN_COMPLEXITY:iv(G) & The design complexity of a module \\
\hline & DESIGN_DENSITY & Design density is calculated as: $\mathrm{iv}(\mathrm{G}) / \mathrm{v}(\mathrm{G})$ \\
\hline & ESSENTIAL_COMPLEXITY:ev(G) & The essential complexity of a module \\
\hline & ESSENTIAL_DENSITY & Essential density is calculated as: $(\mathrm{ev}(\mathrm{G})-1) /(\mathrm{v}(\mathrm{G})-1)$ \\
\hline & MAINTENANCE_SEVERITY & Maintenance Severity is calculated as: $\operatorname{ev}(\mathrm{G}) / \mathrm{v}(\mathrm{G})$ \\
\hline & MODIFIED_CONDITION_COUNT & $\begin{array}{l}\text { The effect of a condition affect a decision outcome by varying that } \\
\text { condition only }\end{array}$ \\
\hline & MULTIPLE_CONDITION_COUNT & Number of multiple conditions that exist within a module \\
\hline & PATHOLOGICAL_COMPLEXITY & $\begin{array}{l}\text { A measure of the degree to which a module contains extremely } \\
\text { unstructured constructs }\end{array}$ \\
\hline
\end{tabular}




\begin{tabular}{|l|l|l|}
\hline \multirow{4}{*}{ others } & $\begin{array}{l}\text { NORMALIZED_CYLOMATIC_COMP } \\
\text { LEXITY }\end{array}$ & $\mathrm{v}(\mathrm{G}) /$ NUMBER_OF_LINES \\
\cline { 2 - 3 } & $\begin{array}{l}\text { GLOBAL_DATA_COMPLEXITY:gdv } \\
\text { G) }\end{array}$ & $\begin{array}{l}\text { the ratio of cyclomatic complexity of a module's structure to its } \\
\text { parameter_count }\end{array}$ \\
\cline { 2 - 3 } & GLOBAL_DATA_DENSITY & Global Data density is calculated as: $g d v(\mathrm{G}) / \mathrm{v}(\mathrm{G})$ \\
\cline { 2 - 3 } & CYCLOMATIC_DENSITY & $\mathrm{v}(\mathrm{G}) /$ NCSLOC \\
\hline
\end{tabular}

Table 2 Metrics used in this study [1]

\subsection{Data Mining Techniques}

Generally, data mining (sometimes called knowledge discovery [11]) is the process of analyzing data from different dimensions and summarizing it into useful information. Although there are many different descriptions for this process, rough procedure can be illustrated as pre-processing the raw data, mining the data, and interpreting the results.

\subsubsection{Pre-Processing the Data}

The raw data in the real world is noisy, that is why we need pre-processing procedure to provide quality data, and then to achieve quality mining results and quality decisions. The preparation of incomplete, inconsistent and noisy data comprises the majority of the work in a data mining application, probably $90 \%$. The tasks in data pre-processing include data cleaning, integration, transformation, reduction and discretization.

At integration step, data from multiple sources are integrated and combined. Detecting and resolving data value conflicts, as well as removing duplicates and abundant data are the key tasks for this part. 
At transformation step, data normalization, aggregation, generalization and other techniques are applied. Normalization refers to scaling attribute values to fall within a specified range. Aggregation indicates moving up in the concept hierarchy on numeric attributes and generalization stands for moving up in the concept hierarchy on nominal attributes.

At reduction step, the number of attribute, attribute values and tuples is reduced in order to obtain a smaller volume of data set but yet produce the same or similar analytical results. Attribute subset selection can be used to choose a minimum set of attributes (features) that is sufficient for the data mining task. Sampling can also be used to select a representative subset of the data, but simple random sampling method may have poor performance in conjunction with skewed data.

At descretization step, the continuous features or attributes of data set are converted into descretized or nominal features, since some data mining algorithms only accept categorical attributes. Typically, there are two types of discretization, unsupervised discretization in which the class variable is not used and supervised discretization, in which the value of class variable is used. Unsupervised discretization involves binning methods, wherein equalinterval (equal width) binning splits the whole range of numbers in intervals with equal size while equal-frequency (equal depth) binning uses intervals containing equal number of values. Supervised discretization relates to entropy (information)-based discretization which recursively splits intervals until the information gain of the resulting split "tells" it to stop. 


\subsubsection{Mining the data}

The goal of data mining is to discover useful or interesting models for the user. Commonly, it involves four types of tasks [11]: association rules, regression model, classification and clustering.

Association rule mining, proposed by Agrawal et al, in 1993 [12], is data mining model studied extensively by the database and data mining community, which assumes all data are categorical. Normal association rule mining does not have any target. It will find all possible rules which exist in data and satisfy a user-specified minimum support and a user-specified minimum confidence at the same time.

Regression is the best-known statistical technique that the data mining community utilizes. Basically, regression is to develop a mathematical model that fits the numeric data set. The simplest form of regression, linear regression, uses the model of a straight line $(y=a x+b)$ and determines the suitable values for $a$ and $b$ to predict the value of $y$ based upon a given value of $x$. Other advanced methods, such as logistic regression, allow the use of

more complex models, such as a logistic function $f(x)=\frac{1}{1+e^{-z}}$. The major limitation of this technique is that it only works well with continuous quantitative data.

Classification is a data mining technique used to predict categorical class labels for data instances, and then classify data (construct a model) based on training set and the values (class labels) in a classifying attribute and use it 
in classifying new data. This paper is mainly focus on the usage of classification technique in software metrics, so the detail information about how to construct the classification models and the way to use these models would be discussed later in this chapter.

Clustering is unsupervised classification with no predefined classes. From a machine learning perspective, clusters correspond to hidden patterns and cluster analysis is to group a set of data objects into clusters, the search for clusters is unsupervised learning. $K$-means clustering is one of the simplest methods of cluster analysis, which intends to partition all data objects into $k$ clusters in which each object belongs to the cluster with the nearest mean.

\subsubsection{Interpreting the Results}

The last step of discovering information from data is to interpret the data mining results and verify the patterns produced by all kinds of algorithms we used in the experiment. Not all results found by the data mining algorithms are positive, which requires us to use some statistical methods or other approaches to evaluate them. Commonly used performance measures for the evaluation of data mining algorithms include, but not limited to, Accuracy, Precision/Recall, Receiver Operating Characteristic (ROC) Curve and Area under the Curve (AUC), which will be covered later in this chapter. 


\subsection{Classification and Random Forests}

Unlike clustering, classification is a supervised machine learning method. It builds a concise model of the distribution of class labels in terms of predictor features. We can state the problem as follows: given training data $\mathrm{T}=\left(\mathrm{y}_{\mathrm{n}}\right.$, $\left.\mathrm{x}_{\mathrm{n}}\right), \mathrm{n}=1, \ldots, \mathrm{N}$, where the $y_{n}$ are the responses and $x_{n}$ are predictors, produce a classifier $\mathrm{C}: \mathrm{X} \rightarrow \mathrm{Y}$. This classifier will map any object $x \in \mathrm{X}$ to its true classification label y $\in \mathrm{Y}$ defined by some unknown mapping $\mathrm{M}$ : X $\rightarrow \mathrm{Y}[13][14]$. The process can be seen in Figure 1.

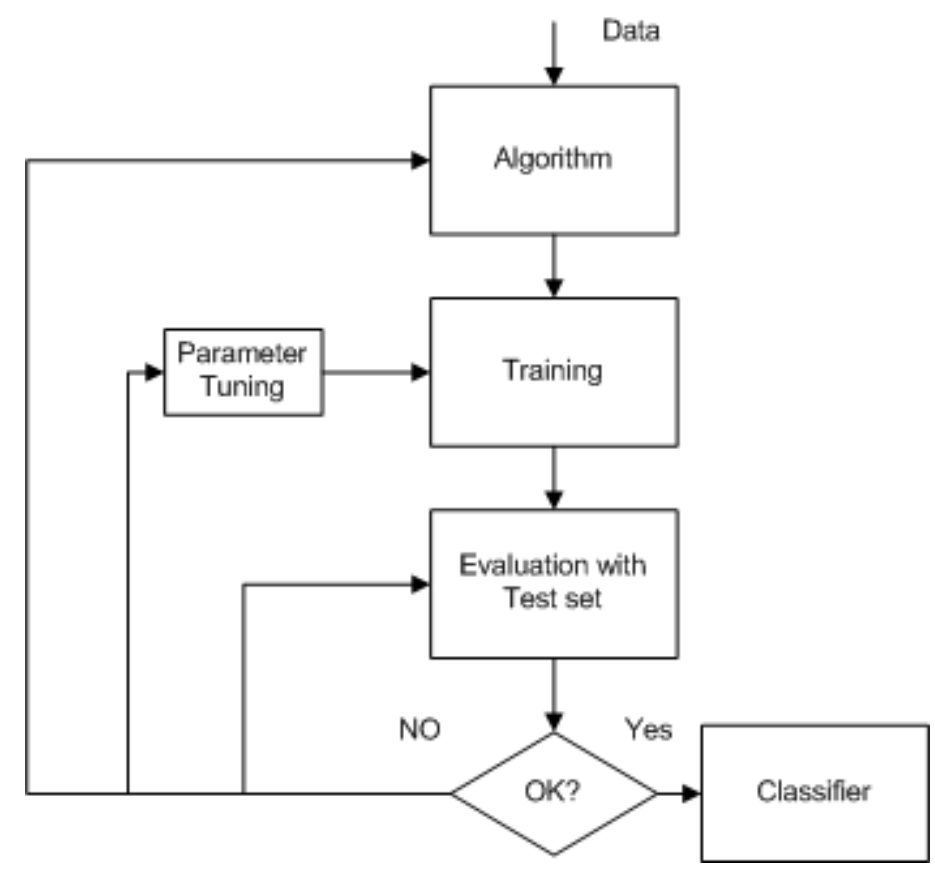

Figure 1 Classification Process

The most widely used classification algorithms include neural network, knearest neighbors, naïve Bayes, boosting and decision tree. In our study, we use Random Forest (RF), an ensemble classifier of decision trees, developed by Leo Breiman and Adele Cutler as the main method. It demonstrates good performance on software engineering studies [15]. Random Forest is a 
classifier consisting of a collection of tree structured predictors, where each tree depends on independent identically distributed random vectors [16]. Each tree constructs as following strategy:

1. Draw $\mathrm{T}$ bootstrap samples from the original data. For each sample, grows a tree;

2. Choose $\mathrm{m}$-- number of variables used to split each node. $\mathrm{m}<<\mathrm{M}$, where $\mathrm{M}$ is the number of variables in the classifier. $\mathrm{m}$ is a constant while growing the tree;

3. When growing a tree at each node, select $m$ variables at random and use them to find the best split. Grow the tree to a maximal extent without pruning.

4. To classify or predict new data, collect the votes from every tree in the forest and then use majority voting to decide on the class label.

The RF uses randomly selected inputs or combinations of inputs at each node to grow each tree. The resulting forests produce highly accurate results for many data sets in an efficient way. It comprises effective method to estimate missing data and maintain accuracy when large portion of data are missing. It can also balance error in class population unbalanced data sets.

The RF is more robust to noise and outliers than many other methods. Thus, the classification accuracy of random forests is more significant over other methods in larger data sets [15]. It can handle large data sets containing 
thousands of input variables without variable deletion, making it a good choice for our study on software engineering metrics data.

\subsection{Evaluation of classification results}

As we generate a suitable classification for the original data, we need to test whether this classification is the best fit for the data. Thus, we need to introduce more evaluation approaches to prove that our algorithms bring us a correct and meaningful interpretation for the original information. Normally, we can use Accuracy, Precision/Recall, Receiver Operating Characteristic (ROC) Curve and Area under the Curve (AUC) as our evaluation methods.

Before we introduce the evaluation methods, we need to explain confusion matrices. In the field of artificial intelligence, confusion matrix is used to represent the instances showing whether the system is confusing among different classes. Each column of the confusion matrix indicates the components in a predicted class, while each row indicates the components in a true class. With the help of confusion matrix, we may observe directly that how many correct predictions we have made and how many failures we have made. Figure 2 shows us an example of confusion matrix. Here, True Positive (TP) and True Negative (TN) are correct classifications. The number of True Positive is the number of items correctly predicted as belonging to the positive class, and the number of True Negative is the number of items correctly predicted as belonging to the negative class. False Positive (FP) occurs when the outcome is incorrectly labeled as positive when it is not and False Negative (FN) occurs when the outcome is incorrectly labeled as negative when it is actually positive. 
In statistical null hypothesis statement, False Negative is known as Type I errors which reject the null hypothesis given that it is actually true. Also, False Positive is known as Type II errors which are failing to reject the null hypothesis given that the alternative hypothesis is actually true.

\begin{tabular}{|c|c|c|}
\hline & Predicted 1 & Predicted 0 \\
\hline \multirow{2}{*}{$\begin{array}{c}\overrightarrow{0} \\
\stackrel{\Xi}{\Xi}\end{array}$} & True & False \\
\hline & Positive & Negative \\
\hline \multirow{2}{*}{$\begin{array}{l}0 \\
0 \\
\Xi \\
\exists\end{array}$} & False & True \\
\hline & Positive & Negative \\
\hline
\end{tabular}

\begin{tabular}{|c|c|c|}
\hline & Predicted 1 & Predicted 0 \\
\hline $\overrightarrow{\underline{a}}$ & $\mathrm{P}(\operatorname{pr} 1 \mid \operatorname{tr} 1)$ & $\mathrm{P}(\operatorname{pr} 0 \mid \operatorname{tr} 1)$ \\
\hline $\begin{array}{c}0 \\
0 \\
\Xi \\
\overrightarrow{\mid l}\end{array}$ & $\mathrm{P}(\operatorname{pr} 1 \mid \operatorname{tr} 0)$ & $\mathrm{P}(\operatorname{pr} 0 \mid \operatorname{tr} 0)$ \\
\hline
\end{tabular}

Figure 2 Confusion Matrix

\subsubsection{Accuracy}

Accuracy is the degree of closeness of a measured or calculated quantity to its actual (true) value [13]. For confusion matrix, the accuracy is all true results out of the whole population. It could be determined by following equation:

Accuracy $=\frac{\text { number.of.(True.Positive }+ \text { True.Negative) }}{\text { number.of.(True.Positive }+ \text { True.Negative }+ \text { False.Positive }+ \text { False.Negative) }}$

On most problems, obtaining Accuracy is easy. However, 99\% accuracy cannot secure a good performance, while $10 \%$ accuracy does not necessarily 
lead to a bad prediction. It depends on the problem and data, in which other elements may count on higher weight.

\subsubsection{Precision and Recall}

In statistical classification task, we also use Precision and Recall to evaluate the basic tradeoff. Precision can be considered as a measure of exactness while Recall is a measure of completeness. In definition, the Precision for a class is the number of true positive divided by the total number of observations labeled as belonging to the positive class, i.e. the sum of true positive and false positive. Recall is defined as the number of true positive over the total number of observations that truly belong to positive class, i.e. the sum of true positive and false negative. They can be demonstrated by following equations:

Precision $=\frac{\text { number.of } \text {.True.Positive }}{\text { number.of.(True.Positive }+ \text { False.Positive })}$

Re call $=\frac{\text { number.of } \text { True.Positive }}{\text { number.of.(True.Positive }+ \text { False.Negative })}$

\subsubsection{ROC Curves}

Receiver Operating Characteristic (ROC) curve is useful for organizing classifiers and provides intuitive way to visualize their performance. In 
addition to a useful performance graphing method, it has properties that make itself useful when learning in the presence of unbalanced classes.

ROC curves are two dimensional graphs which plot True Positive Rate (TP Rate) as a function of False Positive Rate (FP Rate) across all possible experimental threshold settings. They describe the relative tradeoffs between benefits (True Positive) and costs (False Positive). The True Positive Rate (also called Probability of Detection $p d$ and Recall) and False Positive Rate (also called Probability of False Alarm $p f$ ) of the classifier can be estimated as follows:

True.Positive.Rate $=p d=\operatorname{Re}$ call $=\frac{\text { number.of } \text { True.Positive }}{\text { total.Positive }}$

False.Positive.Rate $=p f=\frac{\text { number.of.False.Positive }}{\text { total.Negative }}$

A typical ROC curve will have a concave shape that starts from point $(0,0)$ and ends at $(1,1)$. Point $(0,1)$ represents perfect classification. Informally, one point in ROC curve is better than another if it has higher TP Rate and lower FP Rate.

The area under the ROC curve, abbreviated AUC [17], is a common method to numerically evaluate the performance of different classifier. Since the AUC is a portion of the area of the unit square, its value should fall between 0 and 1. However, since a random guess can produce a diagonal line between $(0,0)$ and $(1,1)$, which has an area of 0.5 , the realistic classifier 
should have an AUC greater than 0.5. Also, a well performed ROC curve for a classifier should lie on the left side of the diagonal line between $(0,0)$ and $(1,1)$.

Within the past two decades, ROC curves and AUC have become the standard tools for analysis and comparison of classifiers for binary classification [18]. The ROC curves conveniently display the tradeoff between TP Rate and FP Rate for two class problems. Thus, when we are dealing with multi-classes problems, we need to make an extension to the ROC analysis. One method for handling multi-classes is to produce $n$ different ROC curves, one for each class [19] [20]. Since AUC is a measure of the discriminability of a pair of classes, the multi-classes' problem will introduce the issue of combining multiple pair wise values, which make it more complicated. Thus, we may calculate AUCs for multi-class problems by generating ROC curve for each class in turn, measuring the area under each curve, and then summing the AUCs weighted by the data: $A U C_{\text {total }}=\sum A U C_{c i} \times p(c i)$, where $\mathrm{AUC}_{\mathrm{ci}}$ is the $\mathrm{AUC}$ for each class and $\mathrm{p}(\mathrm{ci})$ is the probability of this class [19]. 


\section{Chapter 3 Experiment and Analysis}

\subsection{Experiment Design}

We build our predictive models using Random Forest algorithm from Weka package to predict software defects' resolution time. Recall that we use 7 datasets from Metrics Data Program (CM1, JM1, KC1, KC4, PC1, PC3 and PC4), each containing three groups of metrics: design, code and all. We use all the metrics in our study, regardless of the metric groups. The predicted (response) variable is weeks for each defect, which is calculated from getting resolution days by subtracting the opened_time from closed_time in entry_date metric and then dividing the resolution days by 7 . We confirm that only the longest resolution time exists for each faulty module, and then remove the instances without a weeks attribute, and module_id, defect_id, entry_type and entry_date metrics prior to modeling.

We use 10-fold cross validation to fit the predictive model while using Random Forest learner with 500 trees (the default is 10 trees in Weka, an insufficient number based on prior experience). $90 \%$ of the data will work as training set and $10 \%$ as testing set. We will use Accuracy, Precision/Recall and $\mathrm{ROC}$ curves to measure the performance of decision models. For each ROC curve, the AUC is calculated using the Trapezoid rule. Since we need to deal with models of multi-classes, we generate ROC curve for each class

of each data set to visualize the results. The evaluation methods include, but not limited to, weighted average AUC [19]. Recall that weighted average 
AUC is calculated by: $A U C_{\text {weighted }}=\sum A U C_{c i} \times p(c i)$, where $\mathrm{AUC}_{\mathrm{ci}}$ is the AUC for each class and $\mathrm{p}(\mathrm{ci})$ is the probability of this class [19].

In the remainder of this section, we first briefly analyze the response variable, weeks, in our study, and then we execute experiments to determine a suitable discretization method for our data sets. Next, we compare the performance for each model we fit based on Accuracy, ROC curves and AUC. Finally, we conclude the optimal model that best fit most of our datasets.

\subsection{Distribution of Response Variable (Resolution Time)}

The purpose of this study is to fit a model to help predict the resolution time for a specific software engineering project. The best way to help managers control the project is to tell them how many days the engineers need to finish the test procedure. To predict the exact days that we need to solve all defects in a module or project, however, cannot be precise. Thus, we expand the response variable from days to weeks as resolution time and improve the precision of prediction.

After generating the response variable weeks to our dataset, we make a summary of this attribute, see Table 3 . The unit for each cell is weeks. The minimum resolution time for one module in dataset PC4, for example, is 1 week, and the maximum is 91 weeks. This table also gives us the $1^{\text {st }}$ and $3^{\text {rd }}$ quartiles, as well as the median and mean. Median clarifies the middle value

of resolution time while mean exhibits the average. $1^{\text {st }}$ and $3^{\text {rd }}$ quartiles show 
the values on the rank of $1 / 4$ and $3 / 4$ from minimum. To visualize the distribution, we use box plots to show this response variable.

\begin{tabular}{|l|l|l|l|l|l|l|l|}
\hline & CM1 & JM1 & KC1 & KC4 & PC1 & PC3 & PC4 \\
\hline Min & 0 & 0 & 1 & 5 & 1 & 6 & 1 \\
\hline $1^{\text {st }} \mathrm{Q}$ & 5 & 15 & 11 & 15 & 3 & 23 & 12 \\
\hline Median & 14 & 34 & 20 & 20 & 7 & 33 & 48 \\
\hline Mean & 15.03 & 36.84 & 20.03 & 24.47 & 11.86 & 35.31 & 39.12 \\
\hline $3^{\text {rd }} \mathrm{Q}$ & 16 & 50 & 27 & 25 & 11 & 41 & 55 \\
\hline Max & 51 & 131 & 116 & 89 & 74 & 99 & 91 \\
\hline
\end{tabular}

Table 3 Summary of Response Variable weeks

From the box plots we may see that there are many statistical outliers in all datasets except PC4. Also, datasets CM1 and PC4 show more severe skewness. 

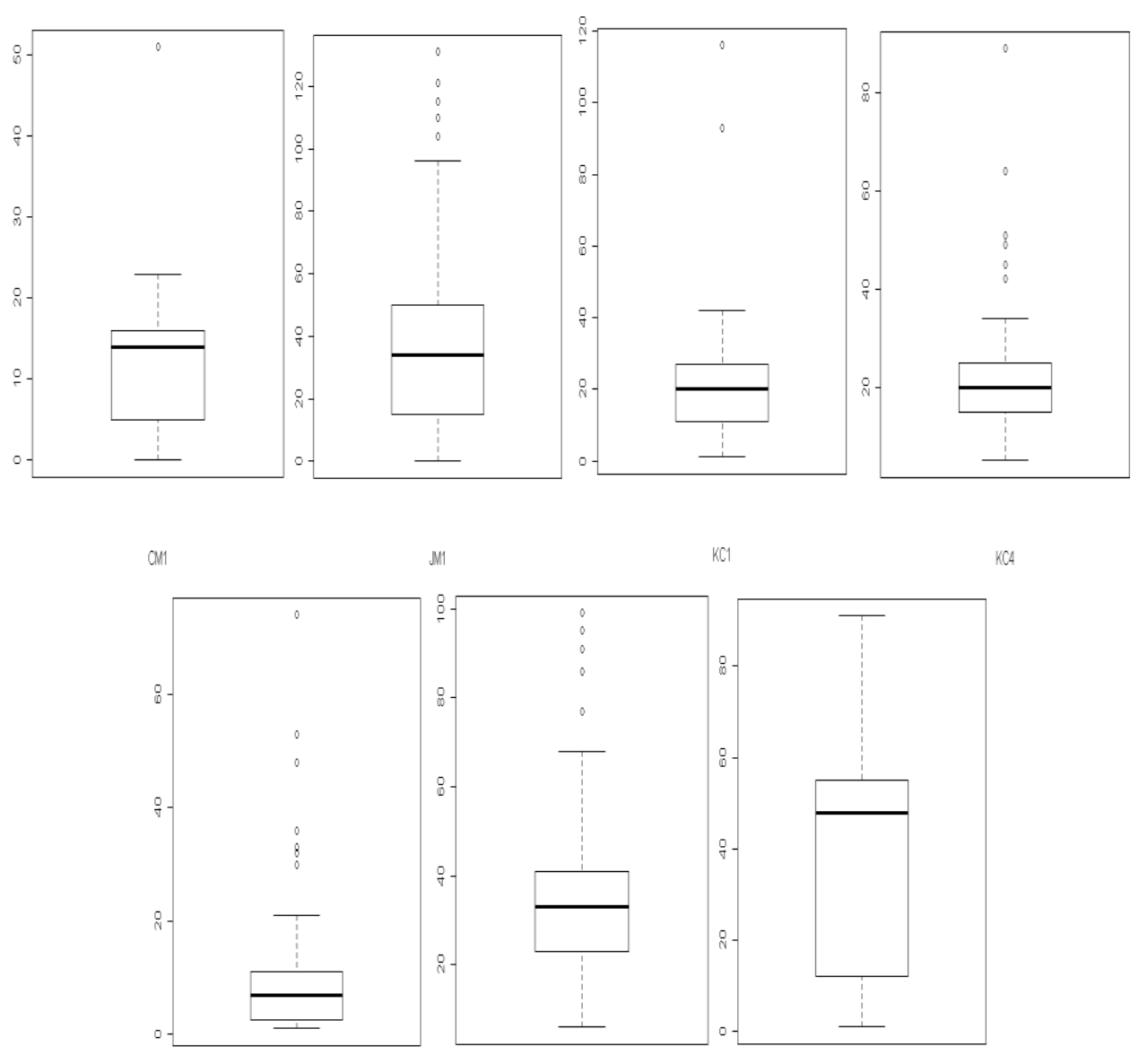

PCI

PC3

PCA

Figure 3 Boxplots of Resolution Time

\subsection{Equal Frequncy vs Equal Width}

Since we need to convert the variable weeks into nominal features, we have to implement a suitable unsupervised discretization method for our datasets. Recall that unsupervised discretization involves binning methods, wherein equal-interval (equal width) binning splits the whole range of numbers in intervals with equal size while equal-frequency (equal depth) binning uses intervals containing equal number of values. Because almost all datasets we are studying involve many statistical outliers which bias the mean value, equal width method would generate bins with major portion of the instances 
and bins with few instances. The consequence is that we may get high accuracy of prediction for one class but poor result for other classes.

We execute an experiment on dataset PC1 to compare the results of equal width and equal frequency discretization method. For the sake of convenience, we choose 3 as our bin number. Then we discretize the response variable weeks in both equal width and equal frequency methods. Table 4 and 5 shows the discretization results. The minimum and maximum resolution times for dataset $\mathrm{PC} 1$ are 0 week and 74 weeks, respectively. The range is 74 weeks. For 3 bin equal width method, we divide the range by 3 to make sure each bin contains the same width, and then we get 3 intervals of 0 to 25.3 weeks, 25.3 to 49.6 weeks, and 49.6 to 74 weeks. For 3 bin equal frequency method, we make sure each bin contains the same number (or close number) of instances. Thus we count the total instance number and divide the total instance by 3 to fit suitable intervals.

\begin{tabular}{|c|c|c|}
\hline \multicolumn{2}{|c|}{$\begin{array}{c}\text { Time } \\
\text { Interval(Weeks) }\end{array}$} & $\begin{array}{c}\# \text { of } \\
\text { Instances }\end{array}$ \\
\hline $\mathrm{a}$ & $0-25.3$ & 53 \\
\hline b & $\begin{array}{c}25.3- \\
49.6\end{array}$ & 8 \\
\hline $\mathrm{c}$ & $49.6-74$ & 2 \\
\hline
\end{tabular}

Table 4 Equal Width

\begin{tabular}{|c|c|c|}
\hline \multicolumn{2}{|c|}{$\begin{array}{c}\text { Time } \\
\text { Interval(Weeks) }\end{array}$} & $\begin{array}{c}\# \text { of } \\
\text { Instances }\end{array}$ \\
\hline $\mathrm{a}$ & $0-3.5$ & 20 \\
\hline $\mathrm{b}$ & $3.5-10.5$ & 22 \\
\hline $\mathrm{c}$ & $10.5-74$ & 21 \\
\hline
\end{tabular}

Table 5 Equal Frequency

We may see that Class $a$ of 3 bin equal width method contains $84 \%$ of the total instances, and the other two only contain $16 \%$. On the contrary, 3 bin equal frequency method assigns almost the same number of instances to each interval. Then, we use the Time Interval (weeks) as our response 
variable to execute Random Forest to predict how many weeks should be used to resolve software defects.

For 3bin equal width method, we calculate a result of Accuracy, Precision, Recall and AUC in Table 6 and a confusion matrix in Table 7. For 3 bin equal frequency method, we produce a result of similar statistics in Table 8 and 9 .

\begin{tabular}{|l|l|l|l|l|l|l|}
\hline Class & $\begin{array}{l}\text { Accuracy } \\
(\%)\end{array}$ & TP Rate & FP Rate & Precision & Recall & AUC \\
\hline a & & 1 & 0.9 & 0.855 & 1 & 0.674 \\
\hline b & & 0.125 & 0 & 1 & 0.125 & 0.705 \\
\hline c & & 0 & 0 & 0 & 0 & 0.275 \\
\hline Average & 85.71 & 0.375 & 0.3 & 0.618 & 0.375 & 0.551 \\
\hline
\end{tabular}

Table 6 3bin Equal Width Result

\begin{tabular}{|c|c|c|c|}
\hline \multicolumn{5}{|c|}{ Confusion Matrix } \\
\hline & $\mathrm{a}$ & $\mathrm{b}$ & $\mathrm{c}$ \\
\hline $\mathrm{a}$ & 53 & 0 & 0 \\
\hline $\mathrm{b}$ & 7 & 1 & 0 \\
\hline $\mathrm{c}$ & 2 & 0 & 0 \\
\hline
\end{tabular}

Table 7 3bin Equal Width

\begin{tabular}{|l|l|l|l|l|l|l|}
\hline Class & $\begin{array}{l}\text { Accuracy } \\
(\%)\end{array}$ & TP Rate & FP Rate & Precision & Recall & AUC \\
\hline a & & 0.45 & 0.233 & 0.474 & 0.45 & 0.71 \\
\hline b & & 0.545 & 0.195 & 0.6 & 0.545 & 0.671 \\
\hline c & & 0.571 & 0.286 & 0.5 & 0.571 & 0.711 \\
\hline Average & 52.381 & 0.522 & 0.238 & 0.525 & 0.522 & 0.697 \\
\hline
\end{tabular}

Table 8 3bin Equal Frequency Result 


\begin{tabular}{|c|c|c|c|}
\hline \multicolumn{5}{|c|}{ Confusion Matrix } \\
\hline & $\mathrm{a}$ & $\mathrm{b}$ & $\mathrm{c}$ \\
\hline $\mathrm{a}$ & 9 & 5 & 6 \\
\hline $\mathrm{b}$ & 4 & 12 & 6 \\
\hline $\mathrm{c}$ & 6 & 3 & 12 \\
\hline
\end{tabular}

Table 9 3bin Equal Frequency

From the result tables and confusion matrices, we can see that although 3 bin Equal Width method yields a better accuracy, it only predicts one correct instance for Class $b$ and $c$. Thus, the $85 \%$ prediction accuracy cannot lead to any meaningful conclusion for our study. Also, the weighted average AUC for 3 classes of 0.55 is only a little higher than a realistic threshold of 0.5 , which further proves that the performance of 3bin Equal Width is really bad. Therefore, for the subsequent experiments, we use Equal Frequency as our discretization methodology.

For the first experiment in our study, we discretize the response variable into 3 bins to verify either Equal Width method or Equal Frequency method is suitable for our model. However, how many bins are suitable for our study is still unknown. Next, we need to implement experiments for all datasets using equal frequency method and then to compare the performance of prediction on different discretized response.

\subsection{3 bin Equal Frequency for All Datasets}

The narrower each time interval is, the more meaningful our prediction can be. Thus, we care about not only the performance of each model, but also the prediction detail each model can give us. In this study, we discretize the response variable (weeks) into 3 bins and execute the experiments for all 
datasets first. The following tables and graphs demonstrate our important statistics and results.

Table 10 shows the discretized response variable for each data set. Table 11 exhibits the confusion matrix and performance result for each data set. Figure 4 displays the ROC curve for each data set.

\begin{tabular}{|c|c|c|c|c|c|c|c|c|}
\hline \multirow[t]{2}{*}{ Classes } & \multicolumn{2}{|c|}{ CM1 } & \multicolumn{2}{|c|}{ JM1 } & \multicolumn{2}{|c|}{ KC1 } & \multicolumn{2}{|c|}{ KC4 } \\
\hline & $\begin{array}{c}\text { Time } \\
\text { Interval } \\
\text { (Weeks) }\end{array}$ & $\begin{array}{c}\# \text { of } \\
\text { Instances }\end{array}$ & $\begin{array}{c}\text { Time } \\
\text { Interval } \\
\text { (Weeks) }\end{array}$ & $\begin{array}{c}\# \text { of } \\
\text { Instances }\end{array}$ & $\begin{array}{c}\text { Time } \\
\text { Interval } \\
\text { (Weeks) }\end{array}$ & $\begin{array}{c}\# \text { of } \\
\text { Instances }\end{array}$ & $\begin{array}{c}\text { Time } \\
\text { Interval } \\
\text { (Weeks) }\end{array}$ & $\begin{array}{c}\# \text { of } \\
\text { Instances }\end{array}$ \\
\hline $\mathrm{a}$ & $0-7.5$ & 24 & $0-27.5$ & 455 & $0-15.5$ & 94 & $0-17.5$ & 20 \\
\hline $\mathrm{b}$ & $7.5-17$ & 37 & $\begin{array}{c}27.5- \\
42.5\end{array}$ & 439 & $\begin{array}{l}15.5- \\
22.5\end{array}$ & 92 & $\begin{array}{l}17.5- \\
21.5\end{array}$ & 20 \\
\hline $\mathrm{c}$ & $18-51$ & 14 & $\begin{array}{c}42.5- \\
131 \\
\end{array}$ & 456 & $\begin{array}{c}22.5- \\
116 \\
\end{array}$ & 100 & $21.5-89$ & 17 \\
\hline \multirow[t]{2}{*}{ Classes } & \multicolumn{2}{|c|}{ PC1 } & \multicolumn{2}{|c|}{ PC3 } & \multicolumn{2}{|c|}{ PC4 } & & \\
\hline & $\begin{array}{c}\text { Time } \\
\text { Interval } \\
\text { (Weeks) }\end{array}$ & $\begin{array}{c}\# \text { of } \\
\text { Instances }\end{array}$ & $\begin{array}{c}\text { Time } \\
\text { Interval } \\
\text { (Weeks) }\end{array}$ & $\begin{array}{c}\# \text { of } \\
\text { Instances }\end{array}$ & $\begin{array}{c}\text { Time } \\
\text { Interval } \\
\text { (Weeks) }\end{array}$ & $\begin{array}{c}\# \text { of } \\
\text { Instances }\end{array}$ & & \\
\hline $\mathrm{a}$ & $0-3.5$ & 20 & $0-27.5$ & 54 & $0-28.5$ & 60 & & \\
\hline $\mathrm{b}$ & $3.5-10.5$ & 22 & $\begin{array}{c}27.5- \\
37.5\end{array}$ & 51 & $\begin{array}{c}28.5- \\
54.5\end{array}$ & 43 & & \\
\hline $\mathrm{c}$ & $10.5-74$ & 21 & $37.5-99$ & 55 & $54.5-91$ & 73 & & \\
\hline
\end{tabular}

Table 10 Instances in Each Bin for 3Bin

From Table 11, we can see that all data sets, except PC3, demonstrate accuracy over $50 \%$. That means more than half of the instances are classified into correct classes. Both $\mathrm{CM} 1$ and $\mathrm{KC} 4$ achieve accuracy of 65\%. Also, weighted average AUC over 0.7 and ROC curves close to upper axes prove that 3Bin Equal Frequency offers a sound performance on prediction of software resolution time for these data sets. The results of accuracy and AUC are consistent of inconsistent. 


\begin{tabular}{|c|c|c|c|c|c|c|c|c|c|c|c|c|c|c|c|c|c|}
\hline \multicolumn{6}{|c|}{ CM1 } & \multicolumn{6}{|c|}{ JM1 } & \multicolumn{6}{|c|}{ KC1 } \\
\hline \multicolumn{4}{|c|}{ Confusion Matrix } & \multicolumn{2}{|c|}{ Result } & \multicolumn{4}{|c|}{ Confusion Matrix } & \multicolumn{2}{|c|}{ Result } & \multicolumn{4}{|c|}{$\begin{array}{l}\text { Confusion } \\
\text { Matrix }\end{array}$} & \multicolumn{2}{|c|}{ Result } \\
\hline Classes & $\mathrm{a}$ & $\mathrm{b}$ & $\mathrm{c}$ & $\begin{array}{c}\text { Accuracy } \\
(\%)\end{array}$ & AUC & & $\mathrm{a}$ & $\mathrm{b}$ & $\mathrm{c}$ & $\begin{array}{c}\text { Accuracy } \\
(\%)\end{array}$ & AUC & & $\mathrm{a}$ & $\mathrm{b}$ & $\mathrm{c}$ & $\begin{array}{c}\text { Accuracy } \\
(\%)\end{array}$ & AUC \\
\hline $\mathrm{a}$ & 18 & 5 & 1 & & 0.8 & $\mathrm{a}$ & 278 & 100 & 77 & & 0.79 & $\mathrm{a}$ & 45 & 27 & 22 & & 0.67 \\
\hline $\mathrm{b}$ & 7 & 28 & 2 & & 0.78 & $\mathrm{~b}$ & 101 & 221 & 117 & & 0.72 & $\mathrm{~b}$ & 35 & 43 & 14 & & 0.71 \\
\hline $\mathrm{c}$ & 4 & 7 & 3 & & 0.79 & $\mathrm{c}$ & 93 & 103 & 260 & & 0.76 & $\mathrm{c}$ & 20 & 16 & 64 & & 0.8 \\
\hline \multicolumn{4}{|c|}{ Weighted Average } & 65.333 & 0.79 & \multicolumn{4}{|c|}{ Weighted Average } & 56.889 & 0.76 & \multicolumn{4}{|c|}{$\begin{array}{l}\text { Weighted } \\
\text { Average }\end{array}$} & 53.147 & 0.73 \\
\hline \multicolumn{6}{|c|}{ KC4 } & \multicolumn{6}{|c|}{ PC1 } & \multicolumn{6}{|c|}{ PC3 } \\
\hline \multicolumn{4}{|c|}{ Confusion Matrix } & \multicolumn{2}{|c|}{ Result } & \multicolumn{4}{|c|}{ Confusion Matrix } & \multicolumn{2}{|c|}{ Result } & \multicolumn{4}{|c|}{$\begin{array}{l}\text { Confusion } \\
\text { Matrix }\end{array}$} & \multicolumn{2}{|c|}{ Result } \\
\hline & $\mathrm{a}$ & $\mathrm{b}$ & $\mathrm{c}$ & $\begin{array}{c}\text { Accuracy } \\
(\%)\end{array}$ & AUC & & $\mathrm{a}$ & $\mathrm{b}$ & $\mathrm{c}$ & $\begin{array}{c}\text { Accuracy } \\
(\%)\end{array}$ & AUC & & $\mathrm{a}$ & $\mathrm{b}$ & $\mathrm{c}$ & $\begin{array}{l}\text { Accuracy } \\
(\%)\end{array}$ & AUC \\
\hline $\mathrm{a}$ & 15 & 5 & 0 & & 0.84 & $\mathrm{a}$ & 9 & 5 & 6 & & 0.71 & $\mathrm{a}$ & 21 & 16 & 17 & & 0.61 \\
\hline $\mathrm{b}$ & 7 & 11 & 2 & & 0.78 & $\mathrm{~b}$ & 4 & 12 & 6 & & 0.67 & $\mathrm{~b}$ & 15 & 18 & 18 & & 0.57 \\
\hline $\mathrm{c}$ & 2 & 4 & 11 & & 0.84 & $\mathrm{c}$ & 6 & 3 & 12 & & 0.71 & $\mathrm{c}$ & 17 & 11 & 27 & & 0.66 \\
\hline \multicolumn{4}{|c|}{ Weighted Average } & 64.912 & 0.82 & \multicolumn{4}{|c|}{ Weighted Average } & 52.381 & 0.7 & \multicolumn{4}{|c|}{$\begin{array}{l}\text { Weighted } \\
\text { Average }\end{array}$} & 40 & 0.61 \\
\hline & & & & & & \multicolumn{6}{|c|}{ PC4 } & & & & & & \\
\hline & & & & & & \multicolumn{4}{|c|}{ Confusion Matrix } & \multicolumn{2}{|c|}{ Result } & & & & & & \\
\hline & & & & & & & $\mathrm{a}$ & $\mathrm{b}$ & $\mathrm{c}$ & $\begin{array}{c}\text { Accuracy } \\
(\%)\end{array}$ & AUC & & & & & & \\
\hline & & & & & & $\mathrm{a}$ & 25 & 18 & 17 & & 0.7 & & & & & & \\
\hline & & & & & & $\mathrm{b}$ & 18 & 14 & 11 & & 0.71 & & & & & & \\
\hline & & & & & & $\mathrm{c}$ & 14 & 5 & 54 & & 0.79 & & & & & & \\
\hline & & & & & & & eighte & $\mathrm{dAve}$ & age & 53.977 & 0.74 & & & & & & \\
\hline
\end{tabular}

Table 11 Confusion Matrices \& Results for 3Bin 


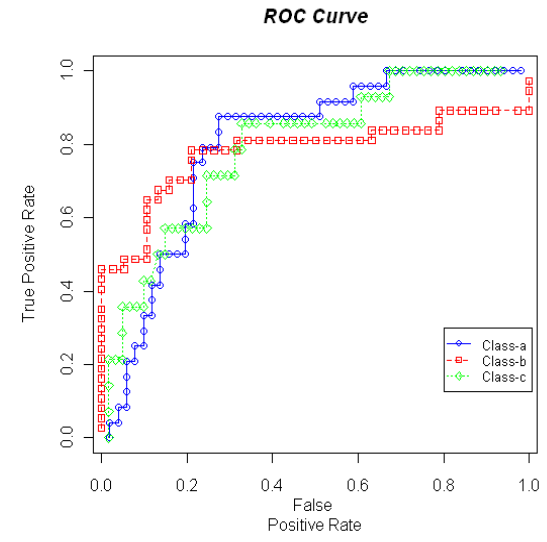

CM1

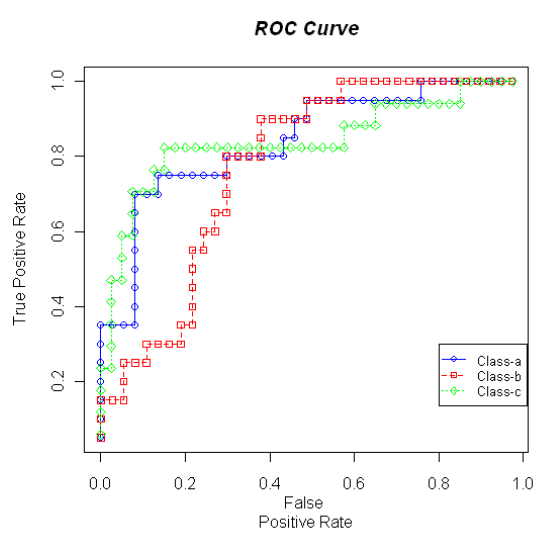

KC4

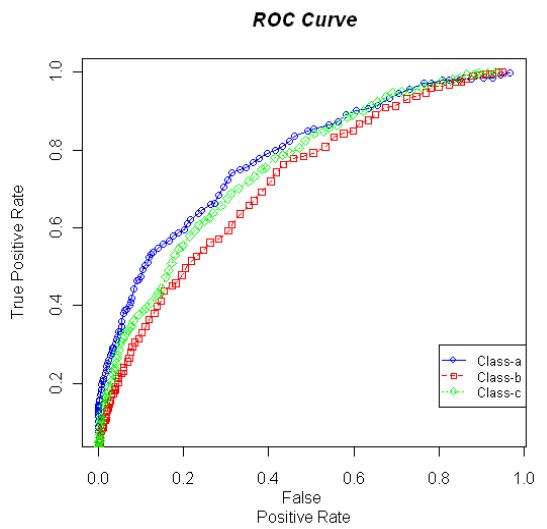

JM1

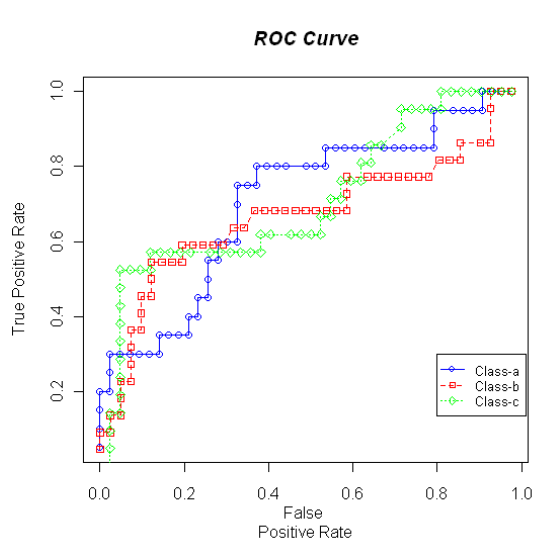

PC1

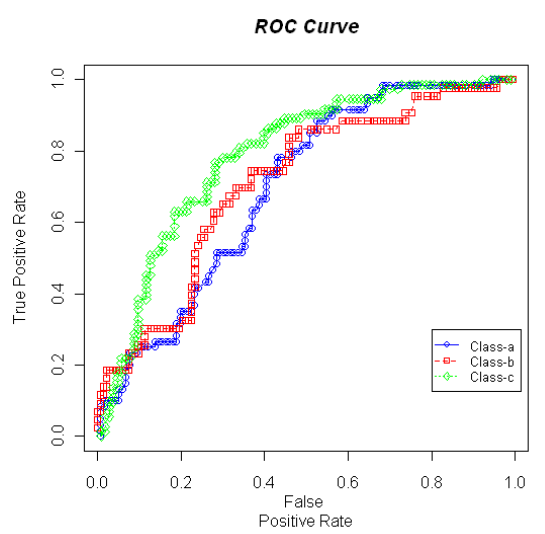

PC4

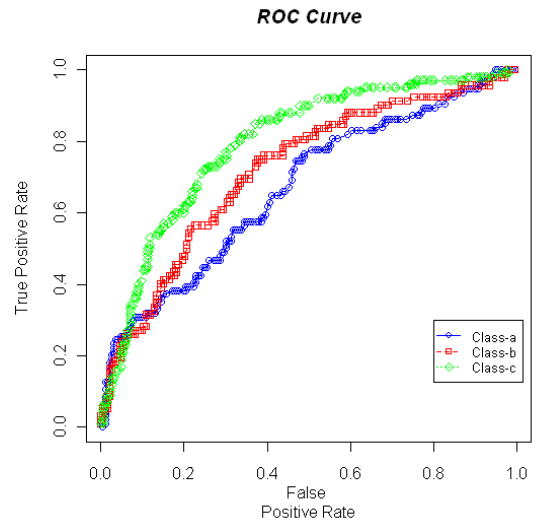

$\mathrm{KC} 1$

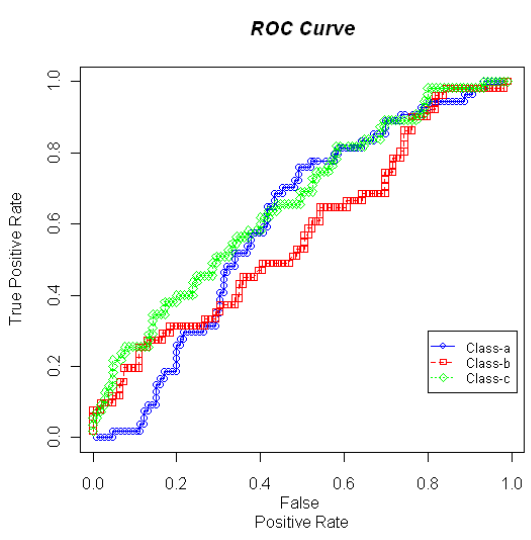

PC3

Figure 4 ROC Curves for 3Bin 


\subsection{Bin Equal Frequency vs 3Bin vs 2Bin}

In previous experiment, we evaluate the performance of 3Bin Equal Frequency method. In this study, we want to compare the impact of different class (bin) numbers on prediction performance. The bin numbers are 5 bins (denoted by 5Bin), 3 bins (3Bin) and 2 bins (2Bin).

To clearly compare the performance of $5 \mathrm{Bin}, 3 \mathrm{Bin}$ and $2 \mathrm{Bin}$, we summarize the results into Table 12. In Appendix A, Table 13 and 14 shows the discretized response variable for 5Bin and 2Bin, respectively; Table 15 exhibits the confusion matrices for 5 Bin while Table 16 for 2 Bin. Figure 5 and 6 visually demonstrates the prediction performance for $5 \mathrm{Bin}$ and $2 \mathrm{Bin}$.

In Table 12, we use Accuracy, Recall and AUC to evaluate the performance of the prediction. Here, Recall and AUC are both weighted average for 5 bins and 3 bins equal frequency methods.

\begin{tabular}{|c|c|c|c|c|c|c|c|c|c|}
\hline & \multicolumn{3}{|c|}{5 bins equal frequency } & \multicolumn{2}{c|}{3 bins equal frequency } & \multicolumn{3}{c|}{2 bins equal frequency } \\
\hline Datasets & Accuracy & Recall & AUC & Accuracy & Recall & AUC & Accuracy & Recall & AUC \\
\hline CM1 & 58.667 & 0.5870 & 0.799 & 65.3 & 0.5737 & 0.788 & $78.667^{*}$ & $0.7865^{*}$ & $0.838^{*}$ \\
\hline JM1 & 46.9 & 0.4676 & 0.774 & 56.9 & 0.5613 & 0.756 & $69.7^{*}$ & $0.6970^{*}$ & $0.778^{*}$ \\
\hline KC1 & 40.91 & 0.3998 & 0.7234 & 53.1469 & 0.5287 & 0.727 & $69.5804^{*}$ & $0.6960^{*}$ & $0.771^{*}$ \\
\hline KC4 & 47.368 & 0.4618 & 0.74 & 64.9123 & 0.6490 & $0.819^{*}$ & $71.9298^{*}$ & $0.7105^{*}$ & 0.769 \\
\hline PC1 & 46.0317 & 0.4422 & $0.722^{*}$ & 52.381 & 0.5220 & 0.697 & $61.9048^{*}$ & $0.6195^{*}$ & 0.688 \\
\hline PC3 & 25.625 & 0.2694 & 0.621 & 40 & 0.4110 & 0.614 & $60.625^{*}$ & $0.6005^{*}$ & $0.674^{*}$ \\
\hline PC4 & 47.7273 & 0.4152 & $0.768^{*}$ & 53.9773 & 0.4943 & 0.737 & $65.9091^{*}$ & $0.6590^{*}$ & 0.753 \\
\hline
\end{tabular}

Table 12 Performance Comparison 

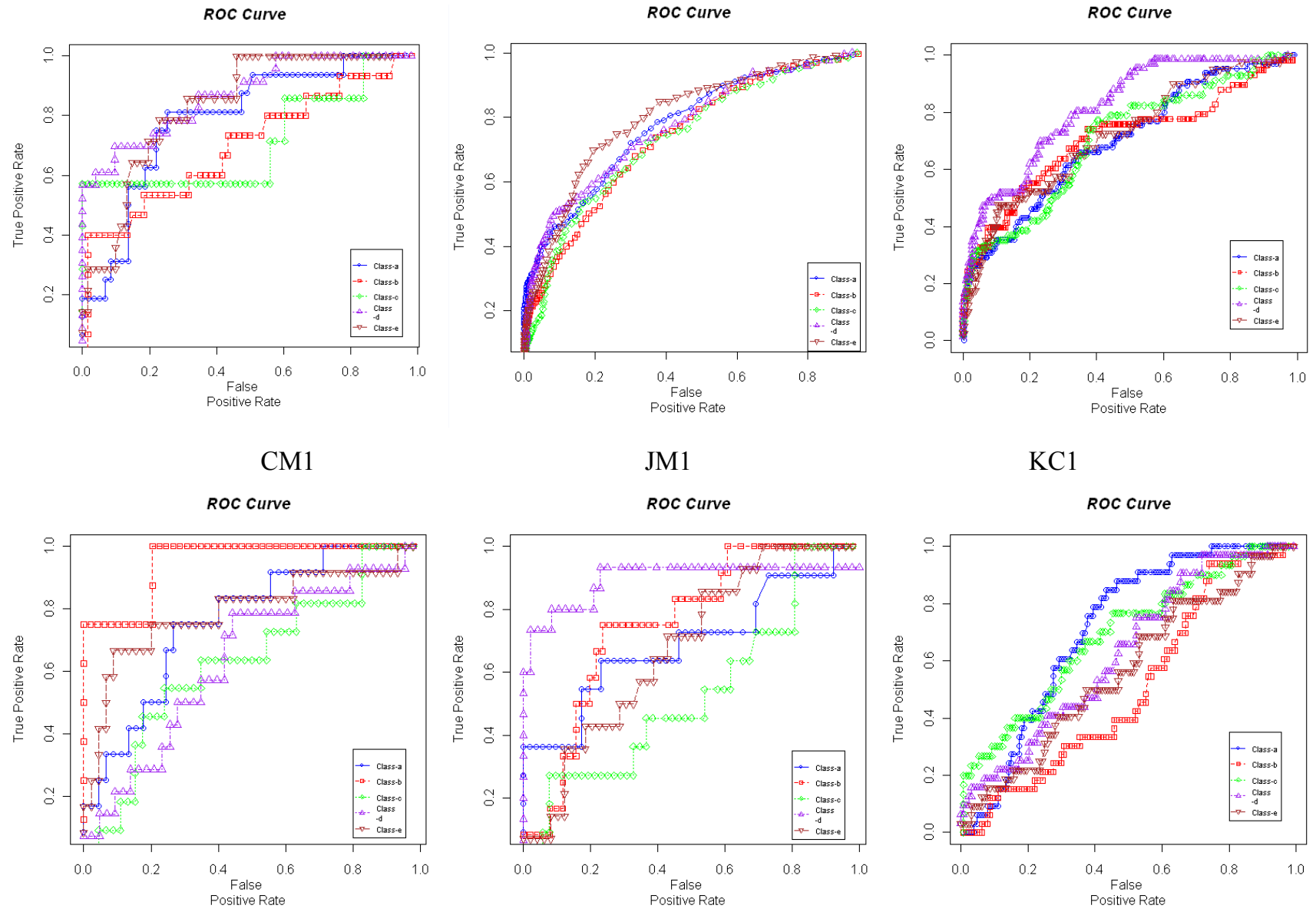

KC4

PC1

PC3

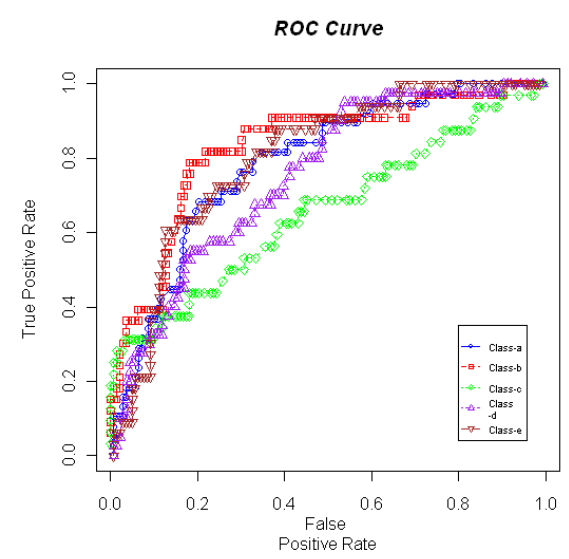

PC4

Figure 5 ROC Curves for 5Bin

We compare the prediction performance among 5 bins, 3 bins and 2 bins equal frequency methods. In Table 12 , the cell with asterisk (*) means it 
performs the best in Accuracy, Recall or AUC when comparing to other methods. 5Bin method shows the worst accuracy. Only one data set achieves accuracy higher than $50 \%$. 2 Bin method demonstrates the best score on accuracy and recall. All three methods exhibit adequate AUC.

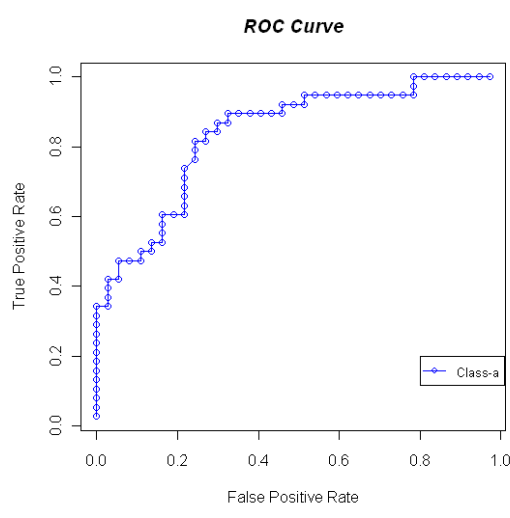

CM1

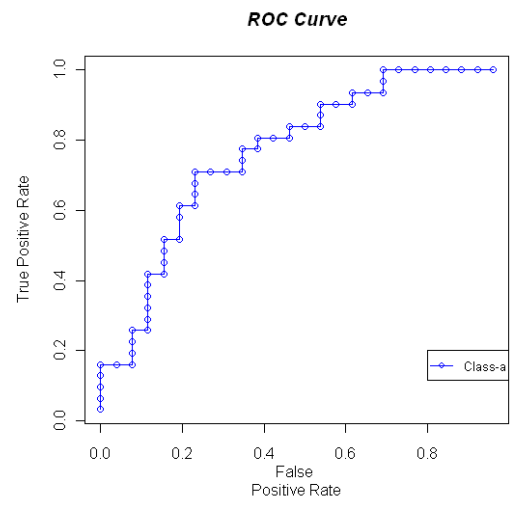

$\mathrm{KC} 4$

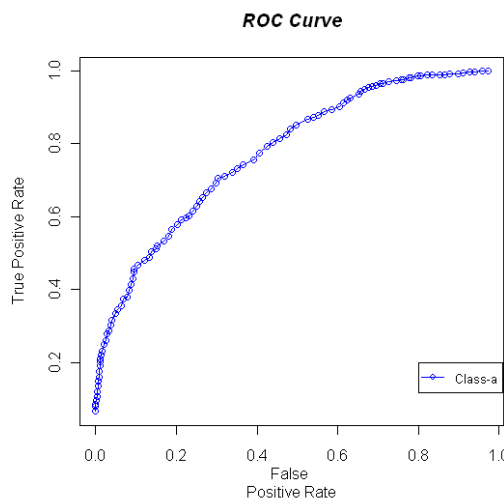

JM1

ROC Curve

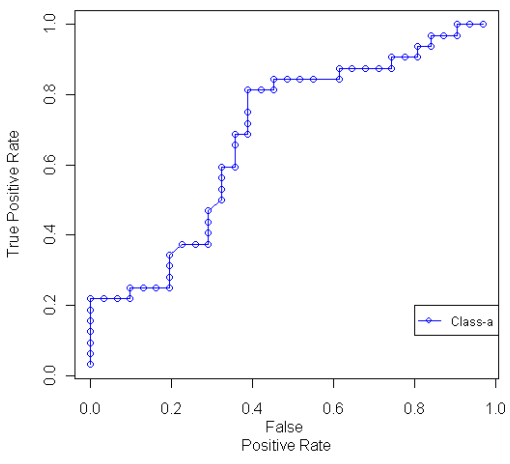

PC1

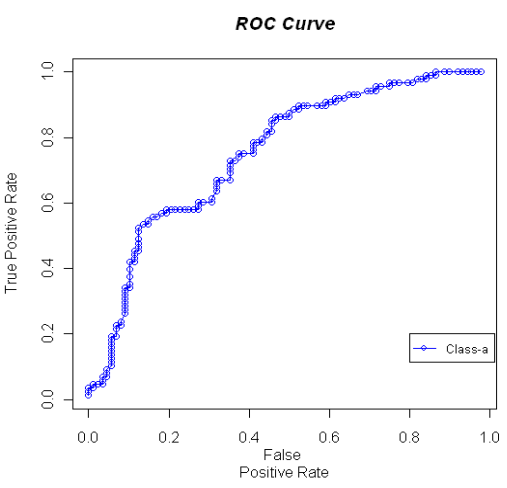

$\mathrm{PC} 4$

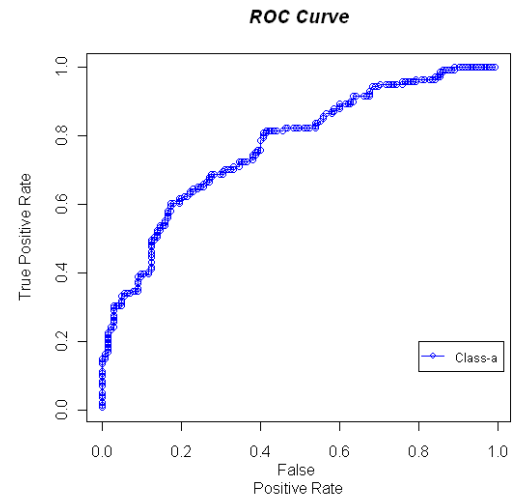

$\mathrm{KC} 1$

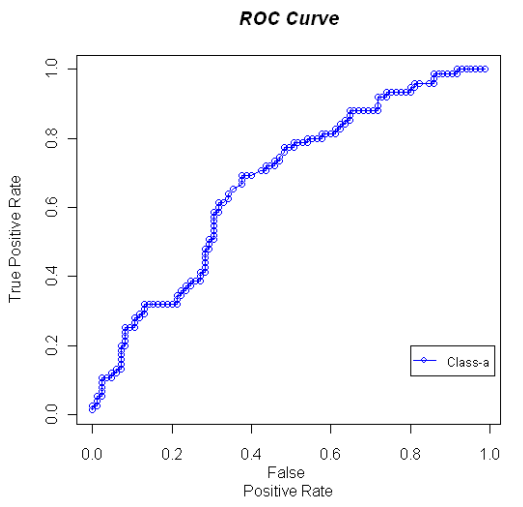

PC3

Figure 6 ROC Curves for 2Bin 
In Figure 5, several classes in data sets $\mathrm{KC} 4, \mathrm{PC} 1$ and $\mathrm{PC} 3$ do not present a good ROC curves since they are too close to the threshold line. This reflects a bad classification for certain instance. In Figure 6, except for data set PC1 and PC3, most ROC curves are in a good shape and imply acceptable performance.

\subsection{Discussion}

Because we use Accuracy to measure the percentage of observations that have been correctly classified, this metric is intended to indicate how well the prediction model works in the sense of how close to true value that the classifications as faulty or not faulty actually are. When the Accuracy is low, most of our predictions are incorrect. Therefore, it is quite important to have a high Accuracy. As we discussed in Experiment Design section, however, a high Accuracy value does not necessarily imply good predictions. Thus we can conclude that although relatively high Accuracy is important and necessary, it is not sufficient to consider a model with high Accuracy as good prediction because of the paucity of faults in the system [21].

Precision focuses on labeling an observation as belonging to one class that does indeed belong to that class, but does not care about the observation in that class which are labeled incorrectly. For this reason, we conclude that low Precision might infer the inefficiency but is not equivalent to poor prediction. On other hand, Recall emphasizes the percentage of true positives that have been correctly identified as such. Therefore, although the 
definition for Precision and Recall are similar to some extent, the consequence of low Recall is far more important than low Precision [21].

As stated above, Thomas J. Ostrand and Elaine J. Weyuker [21] suggested that high Accuracy and high Recall are good measures for a successful prediction. Thus, from above comparison we can see that for 5 bins equal frequency method, the prediction Accuracy and Recall for 6 out of 7 datasets are below $50 \%$ and 0.5 respectively. The low Accuracy of below 50\% shows that more than $50 \%$ observations are labeled as a wrong class, which is a really depressing result. However, it is understandable, since 5bin equal frequency method discretizes the response into 5 bins which make the width of each interval narrower and more difficult to specify.

In contrast, the Accuracy and Recall for 3 bins and 2 bins equal frequency methods are better for analysis. Although 2 bins equal frequency method demonstrates much higher scores for these two metrics, both methods yield similar and favorable ROC curves and AUC. According to the result of AUC, only one dataset using 2 bins equal frequency method is superior to 3 bins equal frequency method by $5 \%$. For other datasets, the differences are not distinct and even the performance of 2 datasets using 3 bins method is better. 

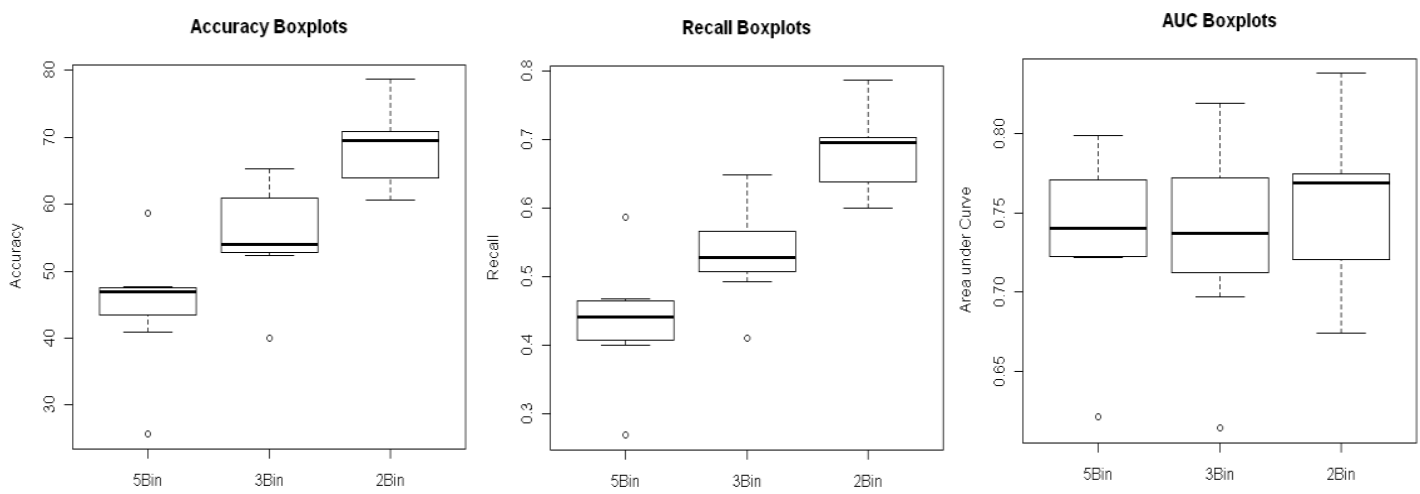

Figure 7 Performance Comparison Boxplot

Figure 7 graphically depicts numerical data distributions of Accuracy, Recall and AUC for 5Bin, 3Bin and 2Bin methods. It shows the smallest instance, lower quartile, median, upper quartile and the largest instance. The line inside the box displays the median which follows the central tendency. Based on these plots, 2Bin method is significantly superior to 3 Bin and 5 Bin methods upon Accuracy and Recall. All three methods present similar AUC distributions.

The reason that 2 bins equal frequency method performs better is understandable, because this approach divide the response into only two bins which make each interval larger than other methods and is easier to classify an observation in this range. For practical usage of this study, we not only want to figure out the best model, but also expect to bring out more interpretation for the prediction. Thus, if we process a prediction which does not require especially high prediction performance, but pursue more meaningful explanation for the data, then 3 bins equal frequency method could be a good fit for the model. 


\section{Chapter 4 Summary and Future Work}

\subsection{Summary}

The goal of this thesis is to study the metrics data which involves different code and design metric features and to find the relationship among these factors, and thus further implement the predicting model to help software development project managers better organize their project schedules.

We have analyzed seven data sets from NASA MDP which offer defect and product metrics. The algorithm we used for classification is Random Forest [16], which has demonstrated superior performance on software faultproneness prediction [15].

First, we identify the discretization method used for classifying response variables into nominal feature. Although Equal Width method generates much better result on Accuracy and other metrics, the skewness of the data suggests that labeling the majority of observations as one class and generating better prediction for this class does not make any meaningful interpretation for the data. This backups our conclusion that pure high performance does not lend any support to the interpretation of prediction. We favor not only the performance of prediction, but also the meaningful explanation for predicted classification. 
Next, after confirming the methodology, we fit the models for the data sets with 5 bins, 3 bins and 2 bins discretization and compare the performance for each method. Our experiments indicate a general trend for MDP data sets that the performance of models which have wider bin width is better. This is understandable, since wider width helps decrease the precision and makes it easier to predict. Although 2 bins discretization shows the best performance, 3 bins discretization also demonstrates acceptable result. Because 3 bins discretization provides more detail information about the classification, in case the best prediction performance does not stand the highest priority, then this model would be a good fit for the data.

Based on the insights we obtained from experiments, we conclude that using predictive model to predict software resolution time based on code and design metrics is reasonable and efficient. The proposed algorithm of Random Forest already generates a favorable result when dealing with binary classification. The algorithm also performs well confronting multiclasses problems, though the decrease of the prediction performance occurs as the increase of the classes we defined.

\subsection{Future Work}

Although our experiments have shown that using Random Forest algorithm to fit a predictive model based on metrics data performs favorably for binary classification, the less prediction detail still has its limitation. Thus, other methodologies need to be implemented in future work to further improve the prediction performance for multi-classes' classification. 
Yue, et al [1] suggested that the metrics in our study should be divided into three groups: design, code, and other metrics. We may fit predictive models with each group of metrics respectively to see the relationship between the predictors and the response variable. With less predictor, the model could be easier, and the connection between predictor variables and response variable may be also easier to construct. No matter whether we use one group of the metrics or all metrics to fit a predictive model, we can always remove irrelevant attributes before we execute the prediction. Statistical methods of Mallows $\mathrm{C}_{\mathrm{p}}$ statistics, Akaike Information Criterion and Bayes Information Criterion [24] can be good measurement of variable selection. Principal Components built-in algorithm in some machine learning software package is also helpful to perform attribution selection and obtain robust principal variables. All above methods can be used in data pre-processing section to improve the prediction performance for our data. 


\section{Reference}

[1] Yue Jiang, Bojan Cukic, Tim Menzies, Nick Bartlow, "Comparing Design and Code Metrics for Software Quality Prediction". pages 11-18. PROMISE '08: Proceedings of the 4th international workshop on Predictor models in software engineering, May 2008

[2] M. Mendonca and N. L. Sunderhaft. "Mining software engineering data: A survey". A DACS state-of-the-art report, Data \& Analysis Center for Software, Rome, NY, 1999.

[3] http://ase.csc.ncsu.edu/dmse/miningalgs.html

[4] Amir Michail. "Data Mining Library Reuse Patterns in User-Selected Applications". ASE 1999.

[5] Amir Michail and Tao Xie. "Helping Users Avoid Bugs in GUI Applications". ICSE 2005.

[6] William Dickinson, David Leon and Andy Podgurski. "Finding Failures by Cluster Analysis of Execution Profiles". ICSE 2001.

[7] Andy Podgurski, Wassim Masri, Yolanda McCleese, Francis G. Wolff, and Charles Yang. "Estimation of software reliability by stratified sampling". ACM Transactions on Software Engineering and Methodology (TOSEM), v.8 n.3, p.263-283, July 1999.

[8] Andy Podgurski, and Charles Yang, "Partition testing, stratified sampling, and cluster analysis". Proceedings of the 1st ACM SIGSOFT symposium on Foundations of software engineering, p.169-181, December 08-10, 1993.

[9] Erik Linstead, Paul Rigor, Sushil Bajracharya, Cristina Lopes, and Pierre Baldi. "Mining Concepts from Code with Probabilistic Topic Models". ASE 2007

[10] Per Runeson, Magnus Alexandersson, and Oskar Nyholm. "Detection of Duplicate Defect Reports Using Natural Language Processing”. ICSE 2007.

[11] Fayyad, Usama; Gregory Piatetsky-Shapiro, and Padhraic Smyth (1996). "From Data Mining to Knowledge Discovery in Databases".

[12] R. Agrawal, T. Imielinski, A. Swami. "Mining Association Rules Between Sets of Items in Large Databases", SIGMOD Conference 1993: 207-216

[13] http://en.wikipedia.org/wiki/

[14] Leo Breiman, Machine Learning, Wald Lecture I, July 2002 
[15] L. Guo, Y. Ma, B. Cukic, and H. Singh. "Robust prediction of fault-proneness by random forests", $15^{\text {th }}$ International Symposium on Software Reliability Engineering ISSRE'04, pages 417-428, 2004

[16] L. Breiman. Random forests. Machine Learning, 45(1):5-32, October 2001

[17] Bradley, A.P,. "The use of the area under the ROC curve in the evaluation of machine learning algorithms", Pattern Recognition. 30 (7), pages 1145-1159, 1997

[18] J. E. Fieldsend and R. M. Everson. "Formulation and comparison of multi-class ROC surfaces", Proceedings of the ICML 2005 workshop on ROC Analysis in Machine Learning, 2005.

[19] Tom Fawcett, "An introduction to ROC analysis", Pattern Recognition Letters, Volume 27, Issue 8 (June 2006)

[20] Stephan M. Winkler, Michael Affenzeller, Stefan Wagner, "Sets of Receiver Operating Characteristic Curves and their Use in the Evaluation of Multi-Class Classification”, GECCO’06, July 8-12, 2006

[21] Thomas J. Ostrand, Elaine J. Weyuker, "How to Measure Success of Fault Prediction Models", SOQUA'07, September 3-4, 2007, Dubrovnik, Croatia

[22] Metric data program. NASA Independent Verification and Validation facility, Available from http://MDP.ivv.nasa.gov.

[23] Do-178b and mccabe iq. Available from http://www.mccabe.com/iq research whitepapers.htm.

[24] Julian Faraway, Linear Model with R.

[25] http://promisedata.org/?cat=4 


\section{Appendix A Tables and Matrices}

\begin{tabular}{|c|c|c|c|c|c|c|c|c|}
\hline \multirow[t]{2}{*}{ Classes } & \multicolumn{2}{|c|}{ CM1 } & \multicolumn{2}{|c|}{ JM1 } & \multicolumn{2}{|c|}{$\mathrm{KC} 1$} & \multicolumn{2}{|c|}{ KC4 } \\
\hline & $\begin{array}{c}\text { Time } \\
\text { Interval } \\
\text { (Weeks) }\end{array}$ & $\begin{array}{c}\# \text { of } \\
\text { Instances }\end{array}$ & $\begin{array}{c}\text { Time } \\
\text { Interval } \\
\text { (Weeks) }\end{array}$ & $\begin{array}{c}\# \text { of } \\
\text { Instances }\end{array}$ & $\begin{array}{c}\text { Time } \\
\text { Interval } \\
\text { (Weeks) }\end{array}$ & $\begin{array}{c}\# \text { of } \\
\text { Instances }\end{array}$ & $\begin{array}{c}\text { Time } \\
\text { Interval } \\
\text { (Weeks) }\end{array}$ & $\begin{array}{c}\text { \# of } \\
\text { Instances }\end{array}$ \\
\hline $\mathrm{a}$ & $0-4.5$ & 16 & $0-10.5$ & 293 & $0-7.5$ & 65 & $0-14.5$ & 12 \\
\hline b & $4.5-11.5$ & 15 & $\begin{array}{l}10.5- \\
29.5\end{array}$ & 305 & $7.5-16.5$ & 58 & $\begin{array}{l}14.5- \\
17.5 \\
\end{array}$ & 8 \\
\hline $\mathrm{c}$ & $\begin{array}{c}11.5- \\
15.5\end{array}$ & 7 & $\begin{array}{c}29.5- \\
41.5\end{array}$ & 268 & $\begin{array}{l}16.5- \\
21.5\end{array}$ & 57 & $\begin{array}{l}17.5- \\
20.5\end{array}$ & 11 \\
\hline d & $\begin{array}{c}15.5- \\
17.5\end{array}$ & 23 & $\begin{array}{c}41.5- \\
55.5 \\
\end{array}$ & 245 & $\begin{array}{l}21.5- \\
28.5 \\
\end{array}$ & 66 & $\begin{array}{c}20.5- \\
29.5\end{array}$ & 14 \\
\hline e & $17.5-51$ & 14 & $\begin{array}{c}55.5- \\
131 \\
\end{array}$ & 239 & $\begin{array}{c}28.5- \\
116 \\
\end{array}$ & 40 & $29.5-89$ & 12 \\
\hline \multirow[t]{2}{*}{ Classes } & \multicolumn{2}{|c|}{ PC1 } & \multicolumn{2}{|c|}{ PC3 } & \multicolumn{2}{|c|}{ PC4 } & & \\
\hline & $\begin{array}{c}\text { Time } \\
\text { Interval } \\
\text { (Weeks) }\end{array}$ & $\begin{array}{c}\# \text { of } \\
\text { Instances }\end{array}$ & $\begin{array}{c}\text { Time } \\
\text { Interval } \\
\text { (Weeks) }\end{array}$ & $\begin{array}{c}\text { \# of } \\
\text { Instances }\end{array}$ & $\begin{array}{c}\text { Time } \\
\text { Interval } \\
\text { (Weeks) }\end{array}$ & $\begin{array}{c}\text { \# of } \\
\text { Instances }\end{array}$ & & \\
\hline $\mathrm{a}$ & $0-1.5$ & 11 & $0-21.5$ & 33 & $0-10.5$ & 38 & & \\
\hline b & $1.5-4.5$ & 12 & $\begin{array}{l}21.5- \\
30.5 \\
\end{array}$ & 33 & $\begin{array}{c}10.5- \\
40.5 \\
\end{array}$ & 33 & & \\
\hline $\mathrm{c}$ & $4.5-9.5$ & 11 & $\begin{array}{c}30.5- \\
35.5\end{array}$ & 30 & $\begin{array}{c}40.5- \\
54.5\end{array}$ & 32 & & \\
\hline d & $9.5-13.5$ & 15 & $\begin{array}{c}35.5- \\
47.5\end{array}$ & 32 & $\begin{array}{c}54.5- \\
56.5\end{array}$ & 40 & & \\
\hline e & $13.5-74$ & 14 & $47.5-99$ & 32 & $56.5-91$ & 33 & & \\
\hline
\end{tabular}

Table 13 Instances in Each Bin for 5Bin

\begin{tabular}{|c|c|c|c|c|c|c|c|c|}
\hline \multirow[t]{2}{*}{ Classes } & \multicolumn{2}{|c|}{ CM1 } & \multicolumn{2}{|c|}{ JM1 } & \multicolumn{2}{|c|}{$\mathrm{KC} 1$} & \multicolumn{2}{|c|}{$\mathrm{KC} 4$} \\
\hline & $\begin{array}{c}\text { Time } \\
\text { Interval } \\
\text { (Weeks) }\end{array}$ & $\begin{array}{c}\# \text { of } \\
\text { Instances }\end{array}$ & $\begin{array}{c}\text { Time } \\
\text { Interval } \\
\text { (Weeks) }\end{array}$ & $\begin{array}{c}\# \text { of } \\
\text { Instances }\end{array}$ & $\begin{array}{c}\text { Time } \\
\text { Interval } \\
\text { (Weeks) }\end{array}$ & $\begin{array}{c}\text { \# of } \\
\text { Instances }\end{array}$ & $\begin{array}{c}\text { Time } \\
\text { Interval } \\
\text { (Weeks) }\end{array}$ & $\begin{array}{c}\# \text { of } \\
\text { Instances }\end{array}$ \\
\hline $\mathrm{a}$ & $0-15$ & 38 & $0-34.5$ & 684 & $0-18.5$ & 141 & $0-20.5$ & 31 \\
\hline $\mathrm{b}$ & $16-51$ & 37 & $\begin{array}{c}34.5- \\
131 \\
\end{array}$ & 666 & $\begin{array}{c}18.5- \\
100\end{array}$ & 145 & $20.5-89$ & 26 \\
\hline \multirow[t]{2}{*}{ Classes } & \multicolumn{2}{|c|}{ PC1 } & \multicolumn{2}{|c|}{$\mathrm{PC} 3$} & \multicolumn{2}{|c|}{$\mathrm{PC} 4$} & & \\
\hline & $\begin{array}{c}\text { Time } \\
\text { Interval } \\
\text { (Weeks) }\end{array}$ & $\begin{array}{c}\# \text { of } \\
\text { Instances }\end{array}$ & $\begin{array}{c}\text { Time } \\
\text { Interval } \\
\text { (Weeks) }\end{array}$ & $\begin{array}{c}\# \text { of } \\
\text { Instances }\end{array}$ & $\begin{array}{c}\text { Time } \\
\text { Interval } \\
\text { (Weeks) }\end{array}$ & $\begin{array}{c}\text { \# of } \\
\text { Instances }\end{array}$ & & \\
\hline $\mathrm{a}$ & $0-7.5$ & 32 & $0-32.5$ & 75 & $0-48$ & 88 & & \\
\hline $\mathrm{b}$ & $7.5-74$ & 31 & $32.5-99$ & 85 & $49-91$ & 88 & & \\
\hline
\end{tabular}

Table 14 Instances in Each Bin for 2Bin 


\begin{tabular}{|c|c|c|c|c|c|c|c|c|c|c|}
\hline \multicolumn{6}{|c|}{ CM1 } & \multicolumn{5}{|c|}{ JM1 } \\
\hline & \multicolumn{5}{|c|}{ Confusion Matrix } & \multicolumn{5}{|c|}{ Confusion Matrix } \\
\hline Classes & $\mathrm{a}$ & $\mathrm{b}$ & $\mathrm{c}$ & $\mathrm{d}$ & $\mathrm{e}$ & $\mathrm{a}$ & $\mathrm{b}$ & $\mathrm{c}$ & $\mathrm{d}$ & $\mathrm{e}$ \\
\hline $\mathrm{a}$ & 11 & 3 & 0 & 2 & 0 & 144 & 68 & 37 & 14 & 30 \\
\hline $\mathrm{b}$ & 4 & 6 & 0 & 4 & 1 & 58 & 148 & 46 & 23 & 30 \\
\hline $\mathrm{c}$ & 1 & 1 & 4 & 1 & 0 & 35 & 52 & 114 & 36 & 31 \\
\hline $\mathrm{d}$ & 0 & 2 & 0 & 18 & 3 & 30 & 43 & 37 & 116 & 19 \\
\hline $\mathrm{e}$ & 3 & 1 & 0 & 5 & 5 & 35 & 36 & 35 & 22 & 111 \\
\hline \multicolumn{6}{|c|}{$\mathrm{KC} 1$} & \multicolumn{5}{|c|}{$\mathrm{KC} 4$} \\
\hline & \multicolumn{5}{|c|}{ Confusion Matrix } & \multicolumn{5}{|c|}{ Confusion Matrix } \\
\hline Classes & $\mathrm{a}$ & $\mathrm{b}$ & $\mathrm{c}$ & $\mathrm{d}$ & e & $\mathrm{a}$ & $\mathrm{b}$ & $\mathrm{c}$ & $\mathrm{d}$ & e \\
\hline $\mathrm{a}$ & 23 & 14 & 14 & 6 & 8 & 7 & 3 & 1 & 1 & 0 \\
\hline $\mathrm{b}$ & 15 & 22 & 10 & 9 & 2 & 2 & 6 & 0 & 0 & 0 \\
\hline $\mathrm{c}$ & 12 & 6 & 24 & 11 & 4 & 3 & 1 & 3 & 4 & 0 \\
\hline $\mathrm{d}$ & 7 & 5 & 13 & 36 & 5 & 1 & 0 & 4 & 4 & 5 \\
\hline $\mathrm{e}$ & 6 & 5 & 8 & 9 & 12 & 1 & 1 & 1 & 4 & 5 \\
\hline \multicolumn{6}{|c|}{$\mathrm{PC} 1$} & \multicolumn{5}{|c|}{ PC3 } \\
\hline & \multicolumn{5}{|c|}{ Confusion Matrix } & \multicolumn{5}{|c|}{ Confusion Matrix } \\
\hline Classes & $\mathrm{a}$ & $\mathrm{b}$ & $\mathrm{c}$ & $\mathrm{d}$ & e & $\mathrm{a}$ & $\mathrm{b}$ & $\mathrm{c}$ & $\mathrm{d}$ & e \\
\hline $\mathrm{a}$ & 4 & 1 & 1 & 2 & 3 & 4 & 1 & 1 & 2 & 3 \\
\hline $\mathrm{b}$ & 0 & 5 & 2 & 2 & 3 & 0 & 5 & 2 & 2 & 3 \\
\hline $\mathrm{c}$ & 2 & 1 & 3 & 2 & 3 & 2 & 1 & 3 & 2 & 3 \\
\hline $\mathrm{d}$ & 0 & 1 & 1 & 12 & 1 & 0 & 1 & 1 & 12 & 1 \\
\hline $\mathrm{e}$ & 0 & 3 & 3 & 3 & 5 & 0 & 3 & 3 & 3 & 5 \\
\hline \multicolumn{6}{|c|}{ PC4 } & & & & & \\
\hline & \multicolumn{5}{|c|}{ Confusion Matrix } & & & & & \\
\hline Classes & $\mathrm{a}$ & $\mathrm{b}$ & $\mathrm{c}$ & $\mathrm{d}$ & $\mathrm{e}$ & & & & & \\
\hline $\mathrm{a}$ & 17 & 5 & 4 & 10 & 2 & & & & & \\
\hline $\mathrm{b}$ & 2 & 21 & 6 & 4 & 0 & & & & & \\
\hline $\mathrm{c}$ & 4 & 8 & 12 & 4 & 4 & & & & & \\
\hline $\mathrm{d}$ & 8 & 3 & 1 & 19 & 9 & & & & & \\
\hline $\mathrm{e}$ & 4 & 3 & 1 & 9 & 16 & & & & & \\
\hline
\end{tabular}




\begin{tabular}{|c|c|c|c|c|c|c|c|c|}
\hline \multicolumn{3}{|c|}{ CM1 } & \multirow{2}{*}{\multicolumn{2}{|c|}{$\begin{array}{c}\text { JM1 } \\
\text { Confusion Matrix }\end{array}$}} & \multirow{2}{*}{\multicolumn{2}{|c|}{$\frac{\mathrm{KC} 1}{\text { Confusion Matrix }}$}} & \multirow{2}{*}{\multicolumn{2}{|c|}{$\begin{array}{c}\text { KC4 } \\
\text { Confusion Matrix }\end{array}$}} \\
\hline & \multicolumn{2}{|c|}{ Confusion Matrix } & & & & & & \\
\hline Classes & $\mathrm{a}$ & $\mathrm{b}$ & $\mathrm{a}$ & $\mathrm{b}$ & $\mathrm{a}$ & $\mathrm{b}$ & $\mathrm{a}$ & $\mathrm{b}$ \\
\hline $\mathrm{a}$ & 31 & 7 & 474 & 210 & 99 & 42 & 25 & 6 \\
\hline$b$ & 9 & 28 & 199 & 467 & 45 & 100 & 10 & 16 \\
\hline \multicolumn{3}{|c|}{$\mathrm{PC} 1$} & \multicolumn{2}{|c|}{ PC3 } & \multicolumn{2}{|c|}{$\mathrm{PC} 4$} & & \\
\hline Classes & $\mathrm{a}$ & $b$ & $\mathrm{a}$ & b & $\mathrm{a}$ & b & & \\
\hline $\mathrm{a}$ & 19 & 13 & 38 & 37 & 59 & 29 & & \\
\hline $\mathrm{b}$ & 11 & 20 & 26 & 59 & 31 & 57 & & \\
\hline
\end{tabular}

Table 16 Confusion Matrices for $2 \mathrm{Bin}$

\footnotetext{
John H.

, $c=$ ate: 2010.12.13 12:46:46-05'00'
} 